\title{
Effects of the water desalting by reverse osmosis on the process of formation of water-alcohol mixtures. ${ }^{1} \mathrm{H}$ NMR spectroscopy studies
}

\author{
Oleg Kuzmin ${ }^{1}$, Sergii Suikov ${ }^{2}$, Oleksandra Niemirich ${ }^{1}$, \\ Iryna Ditrich ${ }^{1}$, Iryna Sylka ${ }^{1}$
}

\author{
1 - National University of Food Technologies, Kyiv, Ukraine \\ 2 - L.M. Litvinenko Institute of Physical-Organic Chemistry and Coal Chemistry \\ NAS, Kyiv, Ukraine
}

Keywords:

Reverse osmosis

Ethanol

Water

Mixture

${ }^{1} \mathrm{H}$ NMR

\section{Article history: \\ Received 13.03.2017 \\ Received in revised \\ form 25.05.2017 \\ Accepted 29.06.2017}

\section{Corresponding \\ author:}

Oleg Kuzmin

E-mail:

kuzmin_ovl@

nuft.edu.ua

DOI: $10.24263 / 2304-$

974X-2017-6-2-6

\section{Abstract}

Introduction. The aim of the publication is to study the effect of demineralising of the water by reverse osmosis on the drift of protons of ethanol and water, as well as the stabilization these systems by ${ }^{1} H N M R$ spectroscopy.

Materials and methods. ${ }^{I} H N M R$ analysis was conducted with the usage of the following: FT-NMR Bruker Avance II spectrometer $(400 \mathrm{MHz})$; specially shaped capillary with acetone$d_{6}$; high accuracy ampoules № 507-HP; dispenser; ethyl rectified spirit (ERS); demineralized water by reverse osmosis; wateralcohol mixtures (WAM) from ERS and demineralized water.

Results and discussion. In this paper, we have established some new features in the process of creating WAM that are directly dependent on the demineralization of water by reverse osmosis. The drift of protons of ethanol and water in the process of creating WAM indicates the complex dynamic of the system stabilization processes. A «restoration» of location of hydroxyl proton's signal $(\mathrm{OH})$ of ethanol is not observed during the time interval of 0 to $432 \mathrm{~h}$ after the mixing, with a constant alcohol concentration (WAM's strength - 39,92 \% vol.) and system's temperature control $\left(\mathrm{t}=23,5{ }^{\circ} \mathrm{C}\right)$. A characteristic feature of ethanol $(\mathrm{EtOH})$ and water $\left(\mathrm{H}_{2} \mathrm{O}\right)$ hydroxyl protons in the WAM during the interval of $\tau=12-432 \mathrm{~h}$ is that the signals $\left(\delta_{E t O H}=4,93-\right.$ $5,01 \mathrm{ppm} ; \delta_{H 2 O}=4,33-4,41 \mathrm{ppm}$.) located separately from each other with a difference in a chemical shifts of $\Delta \delta=0,59-0,61 \mathrm{ppm}$. Division of the signals related to the process of reconstruction of water structure that was destroyed by demineralization by reverse osmosis and to set an equilibrated structure of new system. The low exchange rate (separately observed signals of hydroxyl and water) can be related to a significant microheterogeneity of the system and the corresponding barrier effect that reduces the effective rate of protons' exchange.

Conclusion. Experimentally, using the method of ${ }^{1} H N M R$ spectroscopy, the influence of the use of reverse osmosis of water treatment on the spectral characteristics of mobile protons of ethanol and water, as well as the stabilization of the system in the process of creation of water-alcohol mixtures, was established. It is shown that for such systems, the stabilization process of the water-alcohol mixture is simultaneously with the restoration of a network of hydrogen bonds in the aqueous phase of the microheterogeneous medium. 


\section{Introduction}

$N M R$ spectroscopy is widely used in physics research, industry, agriculture and other industries. $N M R$ plays a particularly important role in food chemistry where it used in the study of both simple organic molecules and complex macromolecular structures and their complexes (Minoja, Napoli, 2014; Singh, Blümich, 2016; Hore, 2017) [1, 13, 16]. A large number of articles discuss the use of $N M R$ for research of food products; meat, fish, dairy products, vegetables, fruits, iuices, pastry, cheese, starch, honey and alcohol products (Minoja, Napoli, 2014; Zuriarrain et al, 2015; Youssouf et al, 2017; Campo et al, 2016; Zhu, 2017; Yuan et al, 2017; Diop et al 2012; Tian et al, 2017, Sucupira et al, 2017, Li et al, 2017; Shumilina et al, 2016; Okaru et al, 2017) [1, 2, 11, 12, 14, 15, 17-22]. This method provides comprehensive information with relatively simple obtaining spectra, thus greatly facilitating and accelerating chemical research (Nose et al, 2005; Richards, Hollerton, 2011; Roberts, 2002; Hu et al, 2010) [5-8].

NMR spectroscopy is most commonly applied to the nuclei of lightest isotope of hydrogen ${ }^{l} \mathrm{H}$ (protium, ${ }^{l} \mathrm{H}$ isotope) proton. The first ${ }^{1} \mathrm{H} N M R$ spectra of ethanol $\mathrm{C}_{2} \mathrm{H}_{5} \mathrm{OH}$ was obtained in 1951 (Arnold et al. 1951) [3]. The first ${ }^{l} H$ NMR spectra of $\mathrm{H}_{2} \mathrm{O}$ were obtained in 1946 (Bloch et al. 1946) [4]. At the first glance, it may seem that these are fairly simple organic molecules, at the same time $N M R$ spectras exhibits greate variety (Nose et al, 2005; Richards, Hollerton, 2011; Roberts, 2002; Hu et al, 2010) [5-8] in such characteristics as chemical shift, spin-spin interactions and the effect of chemical exchange (Matsugami et al, 2016; Jora et al, 2017) [9, $10]$.

An ethanol molecule consists of 6 protons located in a 3 proton-containing groups: methyl $\left(\mathrm{CH}_{3}\right)$, methylene $\left(\mathrm{CH}_{2}\right)$ and hydroxyl $(\mathrm{OH})$ with a relative intensity characteristic $\mathrm{CH}_{3}: \mathrm{CH}_{2}: \mathrm{OH}$ $-3: 2: 1$. Nuclear spin-spin interaction is observed between the three proton-containing groups of ethanol, all of which have different resonant frequencies (Roberts, 2002) [7]. " $N$ " number of equivalent protons of one group split the signal of the nearest group into $(n+1)$ lines with the intensity of a Pascal triangle (Richards, Hollerton, 2011) [6]. The ability to observe spin-spin interactions depends on the rate of the intermolecular proton exchange (Jora et al, 2017) [10]. Wherein the hydroxyl proton $(\mathrm{OH})$ of ethanol can interchange with free hydrogen ions (Matsugami et al, 2016) [9]. The hydrogen ions are generated due to self-dissociation of water or traces of acids, alkalis or dissociated ethanol (Jora et al, 2017) [10]. The concentration of free protons is characterized by $\mathrm{pH}$ level.

Vodka - is an alcoholic drink with strength from $37,5 \%$ to $56 \%$, obtained by special mixing ERS with water, with addition of non-volatile ingredients or without them.

In the opinion $\mathrm{Hu}$ et al. (2010) [8] vodka is a fairly simple physicochemical system: a mixture of alcohol and water. However, each brand has its own distinctive taste and features on the molecular level. Research conducted by Hu et al. (2010) [8] confirm that these differences are significant both during the stage of creating WAM, and in the final product - the commercial vodka. The major differences are associated with hydrogen bonds, in particular their strength, as confirmed by various research methods such as ${ }^{1} H$ NMR spectroscopy, FTIR spectroscopy, Raman spectroscopy. ${ }^{I} H N M R$ and FTIR spectroscopy demonstrates the presence of water in the hydrate structure $\mathrm{EtOH} \cdot(5,3 \pm 0,1) \mathrm{H}_{2} \mathrm{O}$. Water can also be observed in WAM as well as in vodka. The authors ( $\mathrm{Hu}$ et $\mathrm{al}, 2010)$ [8] attribute this value with the perception of organoleptic characteristics of vodka.

Lots of attention in the work of $\mathrm{Hu}$ et al, 2010 [8] has been given to ${ }^{I} H$ NMR spectra of hydroxyl proton of $\mathrm{OH}$ water and alcohol. Water protons are represented as narrow singlets with $\delta_{O H}=5 \mathrm{ppm}$. The spectra of some samples are represented by the appearance of a second broadened $\mathrm{OH}$ signal of ethanol at a level of $\delta_{\mathrm{OH}}=5,5 \mathrm{ppm}$. The presence in the samples of a single signal of $\mathrm{OH}$ ethanol (Hu et al, 2010) [8] is attributed to the weak hydrogen bonds of ethanol.

In their paper, the authors (Hu et al, 2010) [8] introduced the concept of «structurability» defined as the ability to maintain structure - a parameter that determines the ability of vodka (alcohol) to streamline its structure. 
The effect of impurities (such as salts, acids, phenols) strengthening the hydrogen bonds in WAM as well as in the finished product such as sake, has been studied by Nose et al (2005) [5]. $\mathrm{Hu}$ et al [8] have identified that the impurity of compounds has an effect on the molecular dynamics in ethanol's hydration process.

Previously, we have conducted primary research of ${ }^{1} H$ NMR WAM, which were described in the work of Kuzmin et al, 2013-2015 [23-26]. The obtained results give grounds to assert a fundamental difference in the behavior of the WAM prepared from the alcohol and water passing through various processes. This may indicate the presence of such features as separate signals of $\mathrm{OH}$-protons of $\mathrm{H}_{2} \mathrm{O}$ and $\mathrm{EtOH}$. Also abnormal waveforms of $\mathrm{CH}_{3}$ and $\mathrm{CH}_{2}$ characterize a product with a lower tasting properties. The presence of the combined signal of $\mathrm{H}_{2} \mathrm{O}+(\mathrm{EtOH})$ and a "clear" form of $\mathrm{CH}_{3}$ and $\mathrm{CH}_{2}$ signals (triplet - for $\mathrm{CH}_{3}$, quartet - for $\mathrm{CH}_{2}$ ) characterizes the WAM with the best tasting properties.

Thus, in the work of Kuzmin O., Sujkov S. et al, 2013 [23] established experimental evidence of instalment nature / (non- instalment) of thermodynamic balance, taking into account the organoleptic characteristics of WAM in dependence on water treatment method and time of system's functioning. However, the questions related to internal mechanism's specification and the rate of establishment of thermodynamic balance depending on type of water used in the process of creating the WAM are remain unsolved.

Therefore, the additional research is required for a detailed study of internal mechanism of thermodynamic balance and insurance in obtaining high quality vodka products - for each type of water separately.

Therefore, the aim of this work is study of drift of ethanol protons (ERS) and water (demineralized by reverse osmosis) in the process of WAM creation.

\section{Materials and methods}

Materials: demineralized water by reverse osmosis water; ERS; WAM from ERS and water demineralized by means of reverse osmosis.

The following characteristics were determined for water demineralized by reverse osmosis: solid residual - $15 \mathrm{mg} / \mathrm{dm}^{3}$; electrical conductivity - 20,7 $\mu \mathrm{S} / \mathrm{cm} ; \mathrm{pH}-5,05$; ORP - "+" 393 $\mathrm{mV}$; total hardness $-<0,05 \mathrm{mM} / \mathrm{dm}^{3}$; permanganate oxidability $-0,46 \mathrm{mg} \mathrm{O} \mathrm{O}_{2} / \mathrm{dm}^{3}$; mass concentration (MC) of sodium $-11,60 \mathrm{mg} / \mathrm{dm}^{3}$; MC of potassium $-<2,0 \mathrm{mg} / \mathrm{dm}^{3}$; $\mathrm{MC}$ of ammonium $-<2,0 \mathrm{mg} / \mathrm{dm}^{3} ; \mathrm{MC}$ of calcium $-<2,0 \mathrm{mg} / \mathrm{dm}^{3} ; \mathrm{MC}$ of magnesium $-<2,0 \mathrm{mg} / \mathrm{dm}^{3}$; total alkalinity $-0,15 \mathrm{mM} / \mathrm{dm}^{3}$.

Characteristics of ERS: volume part of ethanol - 96,37 \%, volume part of water $-3,63 \%$; content of aldehydes in anhydrous alcohol, in recalculation on acetic aldehyde $-1,3 \mathrm{mg} / \mathrm{dm}^{3}$; content of fusel oils in anhydrous alcohol: propyl, isopropyl, butyl, isobutyl and isoamyl - 1,5 $\mathrm{mg} / \mathrm{dm}^{3}$; content of esters in anhydrous alcohol, in recalculation on acetic-ethyl ether $-1,3$ $\mathrm{mg} / \mathrm{dm}^{3}$; content of methanol in anhydrous alcohol $-0,0022 \% \mathrm{vol}$.

WAM made of ERS and process water - demineralized by the reverse osmosis has the following characteristics: alcoholic strength $-39,92 \%$ vol.; electrical conductivity $-3,5 \mu \mathrm{S} / \mathrm{cm}$; ORP - “"” $98 \mathrm{mV}$; pH level - 7,60; content of aldehydes in anhydrous alcohol, in recalculation on acetic aldehyde $-1,8 \mathrm{mg} / \mathrm{dm}^{3}$; content of fusel oils in anhydrous alcohol: propyl, isopropyl, butyl, isobutyl and isoamyl $-1,4 \mathrm{mg} / \mathrm{dm}^{3}$; content of esters in anhydrous alcohol, in recalculation on acetic-ethyl ether $-1,4 \mathrm{mg} / \mathrm{dm}^{3}$; content of methanol in anhydrous alcohol $0,0021 \%$ vol.; alkalinity $-0,4 \mathrm{~cm}^{3} 0,1 \mathrm{M}$ of hydrochloric acid for titration of $100 \mathrm{~cm}^{3}$ sorting; oxidability test -9 min.; taste evaluation $-9,30$ pointa (appearance - colourless liquid without sediment; odor - strong alcoholic; taste - sour and bitter, pungent).

${ }^{1} H$ NMR analysis of WAM was conducted with the usage of the following: FT-NMR Bruker Avance II spectrometer $(400 \mathrm{MHz})$ with operating frequency at ${ }^{1} \mathrm{H}-400 \mathrm{MHz}$; specially shaped capillary with acetone- $\mathrm{d}_{6}$; high accuracy ampoules № 507-HP for high resolution NMR's spectroscopy (400 MHz); dispenser. 
Work methodology (Kuzmin et al, 2013-2015) [23-26]:

1. $0,3 \mathrm{ml}$ of a WAM prepared with a volumetric pipette with a predetermined strength $(40,0$ $\pm 0,2) \%$ vol.

2. External standard which is required for LOCK's system operation is added into an ampoule of special form capillary.

3. ${ }^{I} H N M R$ spectra records and data processing were performed according to the manuals of FT-NMR Bruker Avance II (400 MHz) spectrometer.

\section{Results and discussions}

Spectrum of water $-\mathrm{H}_{2} \mathrm{O}$ (figure 1), ERS (figure 2), WAM (figures 3-23), made of demineralized water prepared by means of osmosis and ERS at a different lifetimes (h) is characterized by a unitary signal of hydroxyl group of $\mathrm{H}_{2} \mathrm{O}$ (figure 1). The sygnal of $\mathrm{H}_{2} \mathrm{O}$ protons - singlet $(s)$, located at $\delta_{\mathrm{H} 2 O}=4,63 \mathrm{ppm}$. Waveform of $\mathrm{H}_{2} \mathrm{O}$ protons - is distorted Gaussian curve, with a broadened base and a slight asymmetry of apex, which is offset from the centerline.

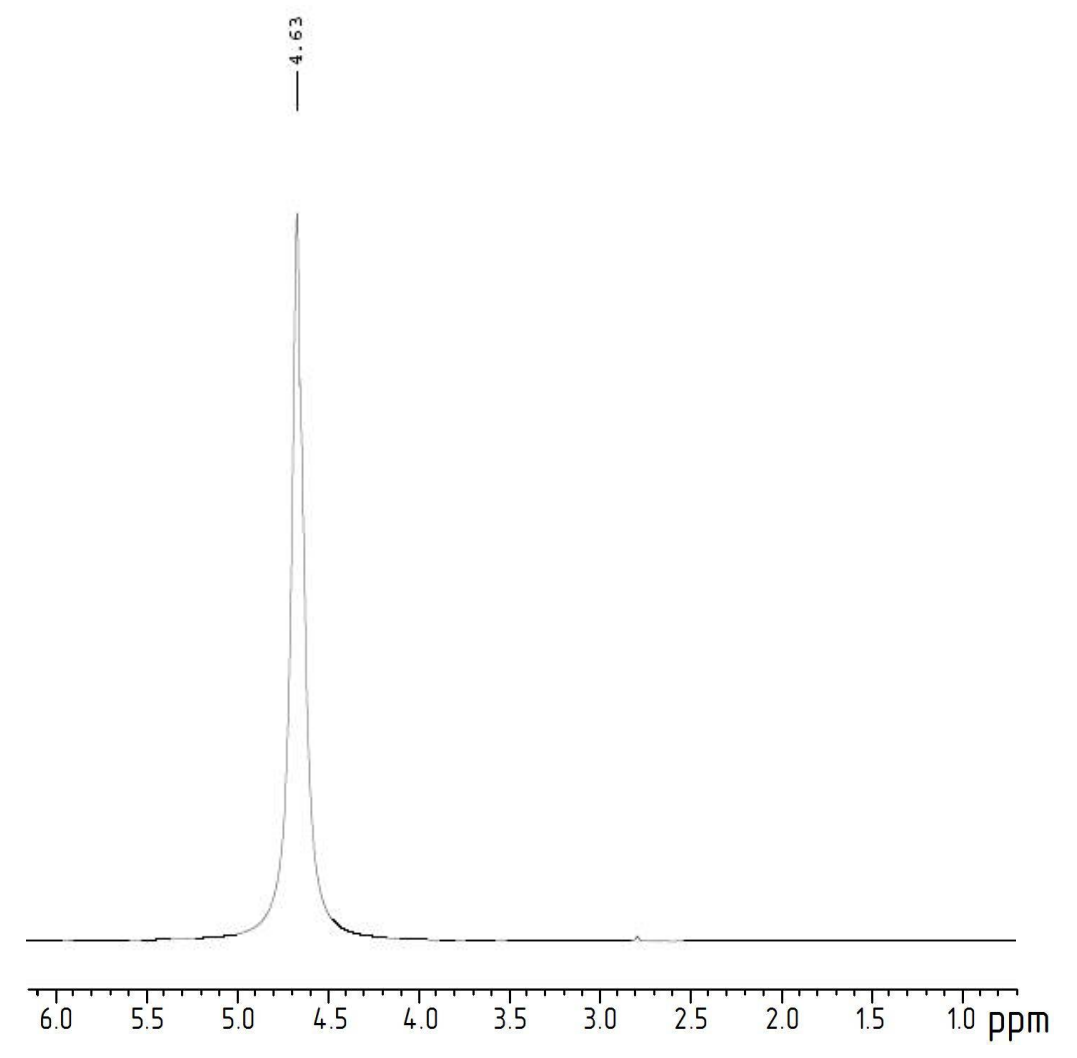

Figure 1. ${ }^{1} \mathrm{H} N M R$ spectra of $\mathrm{H}_{2} \mathrm{O}$-proton of water, prepared in demineralized by reverse osmosis 


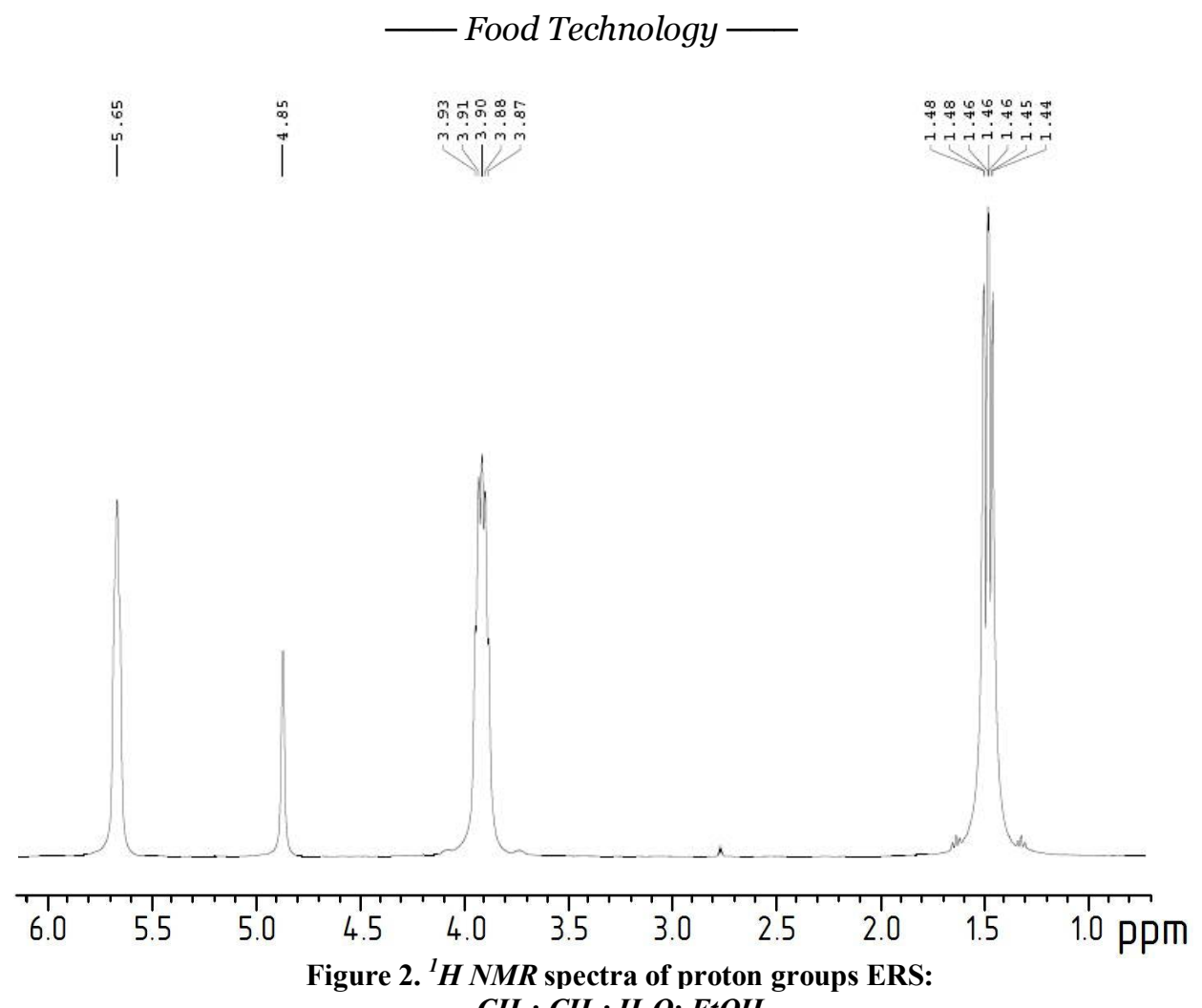

$\mathrm{CH}_{3} ; \mathrm{CH}_{2} ; \mathrm{H}_{2} \mathrm{O} ; \mathrm{EtOH}$

We will analyze the spectra of ERS (figure 2). Hydroxyl group of protons of ERS are represented by two separate peaks. A component of ethanol is represented as a single broad singlet, located in a «low field» with the chemical shift $\delta_{E t O H}=5,65 \mathrm{ppm}$. A component of water proton is represented as singlet with a chemical shift of $\delta_{H 2 O}=4,85 \mathrm{ppm}$. The form of $\mathrm{H}_{2} \mathrm{O}$ protons' signal is a distorted Gaussian curve, with a broadened base and a certain asymmetry. The difference between the $\mathrm{OH}$-proton of ethanol $(\mathrm{EtOH})$ and the proton of water $\left(\mathrm{H}_{2} \mathrm{O}\right)$ in the chemical shifts $-\Delta \delta=0,80 \mathrm{ppm}$.

The analysis of the ${ }^{l} \mathrm{H} N M R$-spectra of protons methyl group of ethanol $\left(\mathrm{CH}_{3}\right)$ allows us to state the following. The protons' methyl group is represented as a septet $(s p)$ with a relative intensity (1:6:15:20:15:6:1). This is abnormity as according to Pascal's triangle and on the assumption of protons' methyl group spin-spin interactions, methylene group's $\left(\mathrm{CH}_{3}\right)$ signal has to be split by an adjacent protons' group $\left(\mathrm{CH}_{2}\right)$ as a triplet $(t)$ with intensity ratio $(1: 2: 1)$. Besides the methylene group $\left(\mathrm{CH}_{2}\right)$, no other group of protons can have observable an effect on the active spectrum of the methyl group $\left(\mathrm{CH}_{3}\right)$.

The analysis of methylene group's $\left(\mathrm{CH}_{2}\right){ }^{l} \mathrm{H} N M R$ 's protons shows the following. The methylene group's protons $\left(\mathrm{CH}_{2}\right)$ are represented as quintet (qi) with the intensity $(1: 4: 6: 4: 1)$. This is an abnormity. Protons of methyl $\left(\mathrm{CH}_{3}\right)$ groups must split the signal of methylene group $\left(\mathrm{CH}_{2}\right)$ into four components and form a quartet $(q)$ with an intensity ratio of 1:3:3:1, as based on the spin-spin interaction. In turn, protons of hydroxyl $(\mathrm{OH})$ groups should split each quartet's component of methylene $\left(\mathrm{CH}_{2}\right)$ group into two components to form a double quartet. The signal of methylene $\left(\mathrm{CH}_{2}\right)$ groups should remain as quartet. This happens due to the absence of observable spin-spin interaction between the hydroxyl $(\mathrm{OH})$ and methylene $\left(\mathrm{CH}_{2}\right)$ groups by the chemical exchange. 


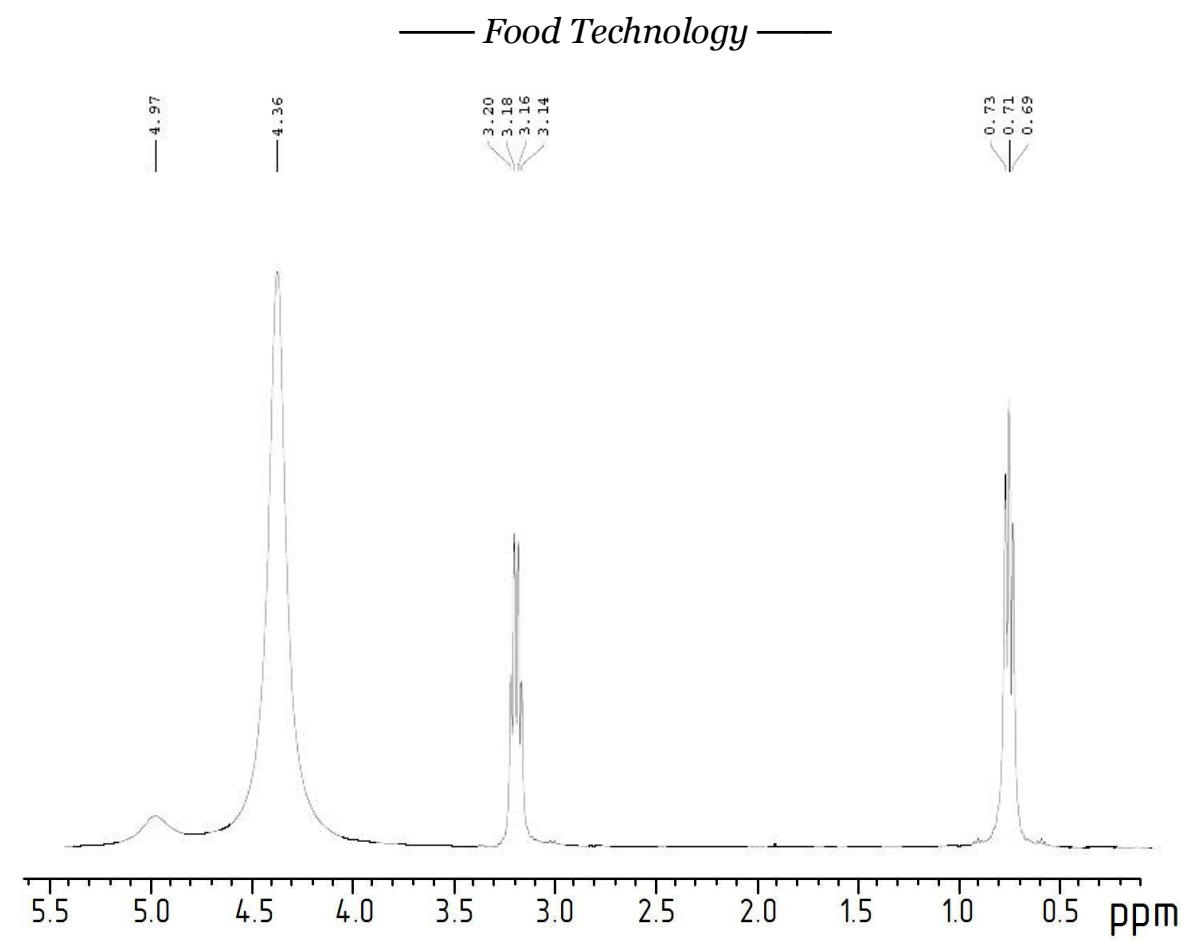

Figure 3. ${ }^{1} \mathrm{H}$ NMR spectra of proton groups of WAM, prepared in demineralized by reverse osmosis water and ERS: $\mathrm{CH}_{3} ; \mathrm{CH}_{2} ; \mathrm{H}_{2} \mathrm{O} ; \mathrm{EtOH}$, dependent from system's functioning time (0 h)

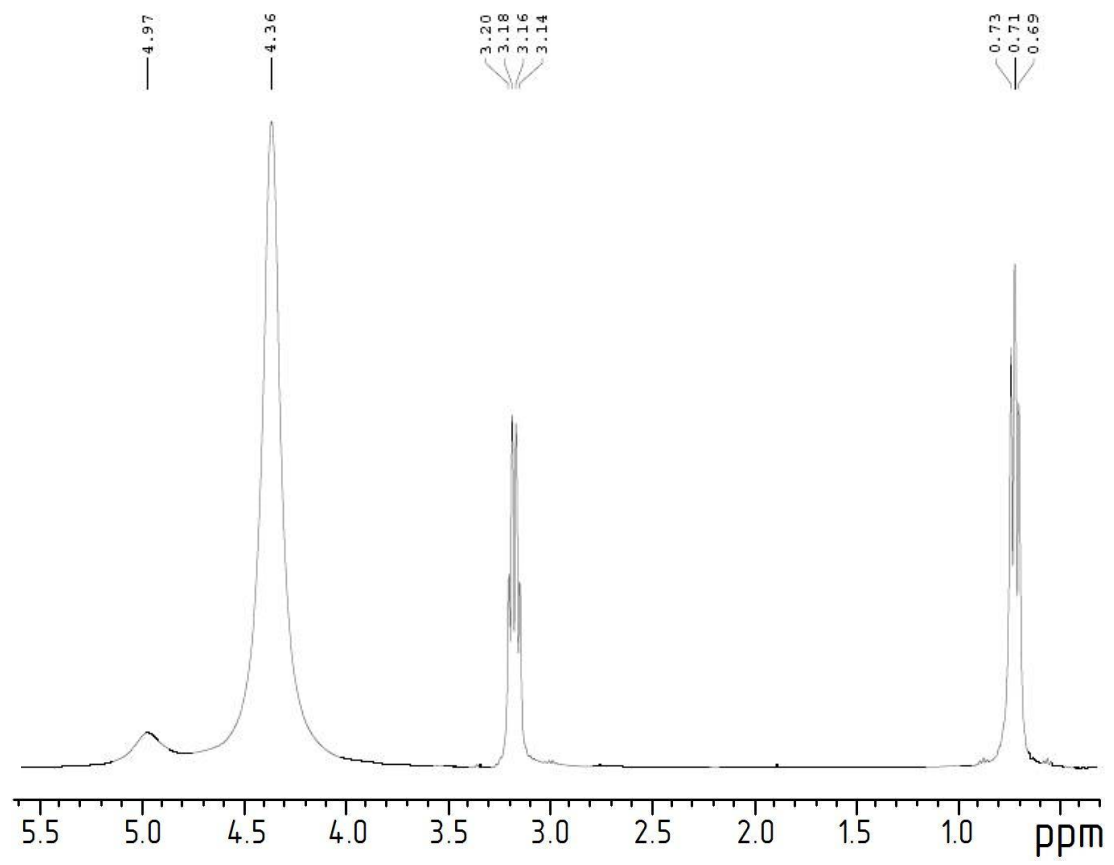

Figure 4. ${ }^{1} \mathrm{H} N M R$ spectra of proton groups of WAM, prepared in demineralized by reverse osmosis water and ERS: $\mathrm{CH}_{3} ; \mathrm{CH}_{2} ; \mathrm{H}_{2} \mathrm{O} ; \mathrm{EtOH}$, dependent from system's functioning time(12h) 


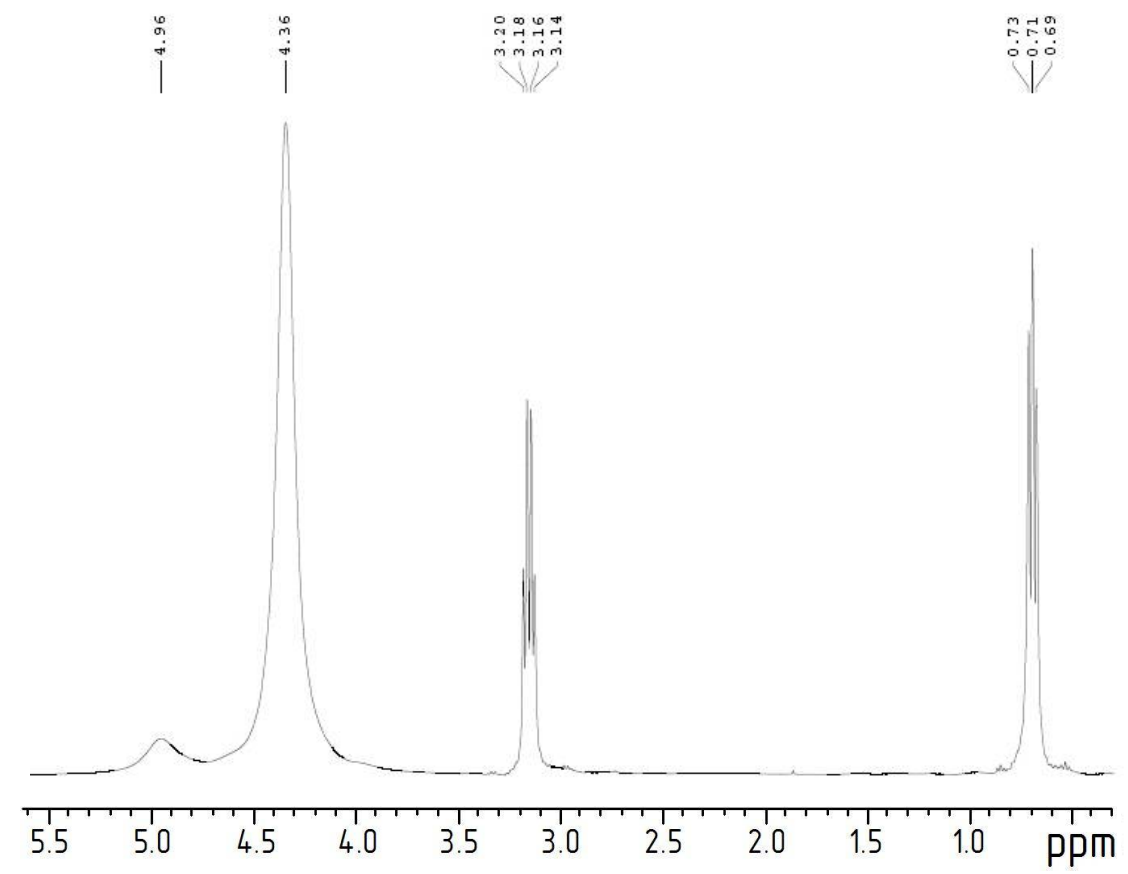

Figure 5. ${ }^{1} H$ NMR spectra of proton groups of WAM, prepared in demineralized by reverse osmosis water and ERS: $\mathrm{CH}_{3} ; \mathrm{CH}_{2} ; \mathrm{H}_{2} \mathrm{O} ; \mathrm{EtOH}$, dependent from system's functioning time (24 h)

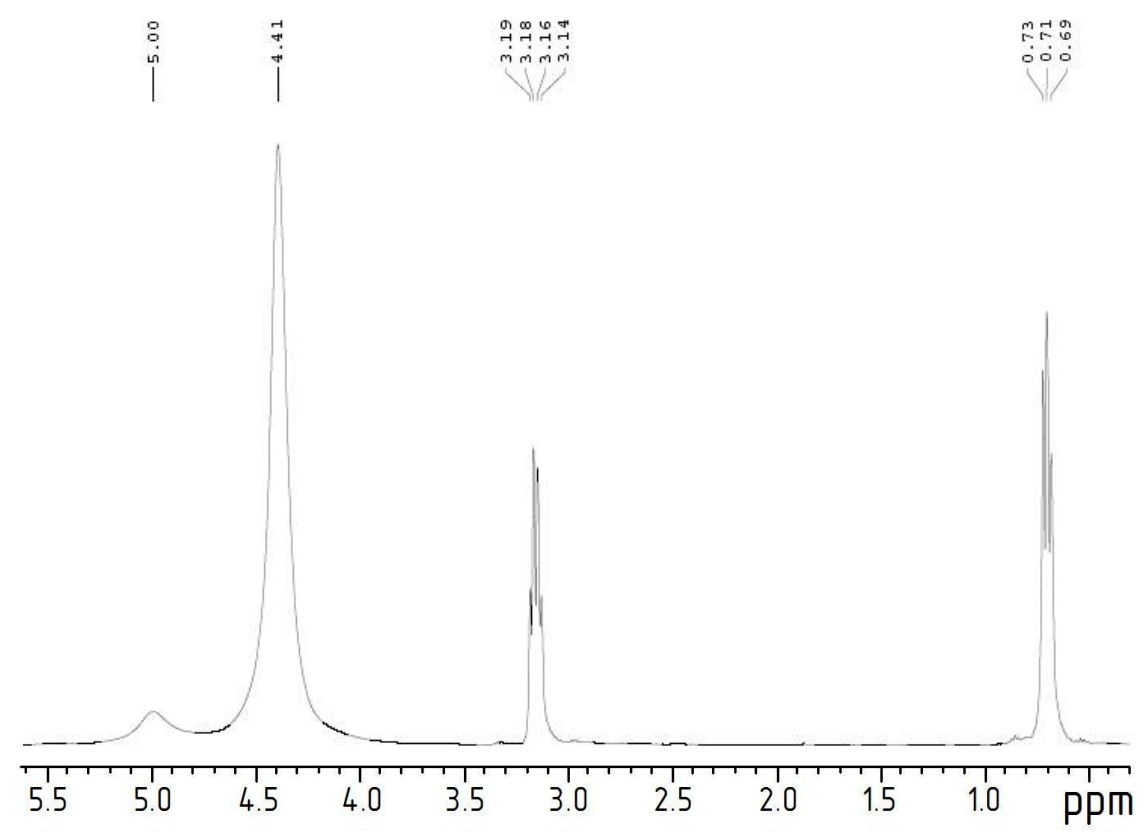

Figure 6. ${ }^{1} H$ NMR spectra of proton groups of WAM, prepared in demineralized by reverse osmosis water and ERS: $\mathrm{CH}_{3} ; \mathrm{CH}_{2} ; \mathrm{H}_{2} \mathrm{O} ; \mathrm{EtOH}$, dependent from system's functioning time (36 h) 


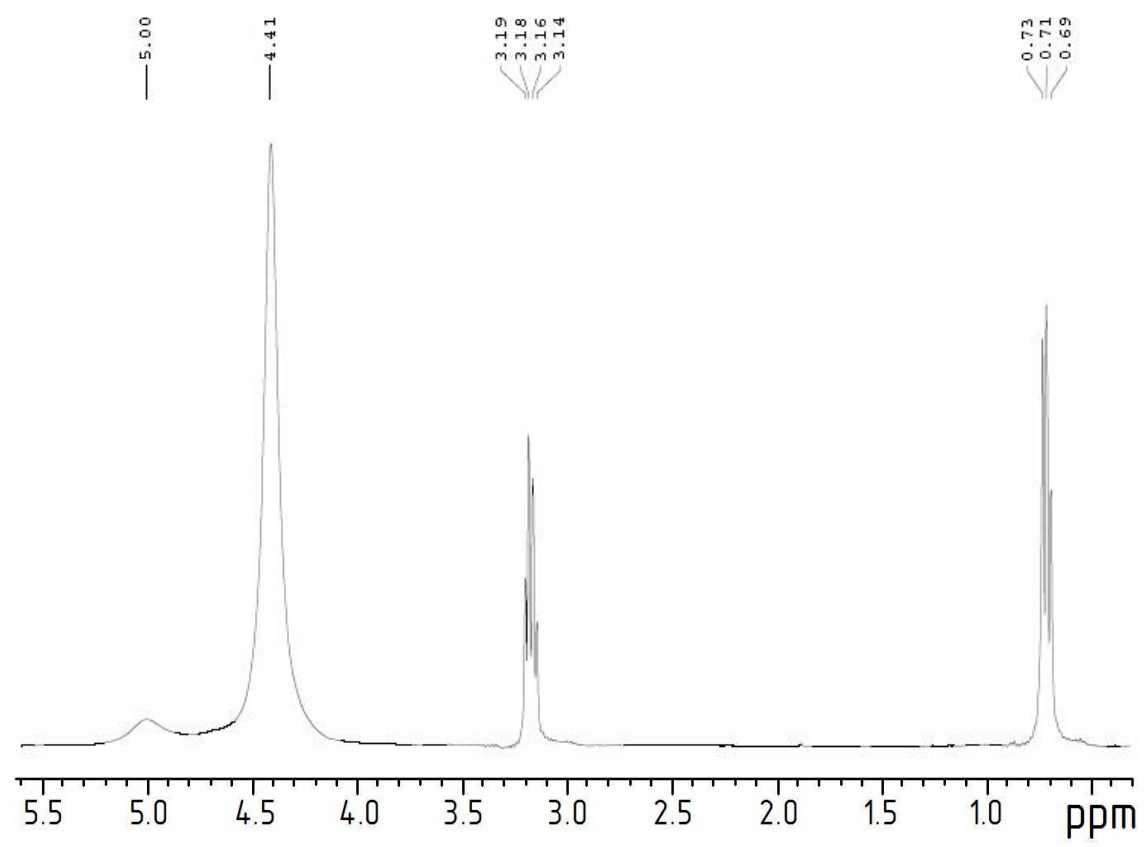

Figure 7. ${ }^{1} \mathrm{H} N M R$ spectra of proton groups of WAM, prepared in demineralized by reverse osmosis water and ERS: $\mathrm{CH}_{3} ; \mathrm{CH}_{2} ; \mathrm{H}_{2} \mathrm{O} ; \mathrm{EtOH}$, dependent from system's functioning time (48 h)

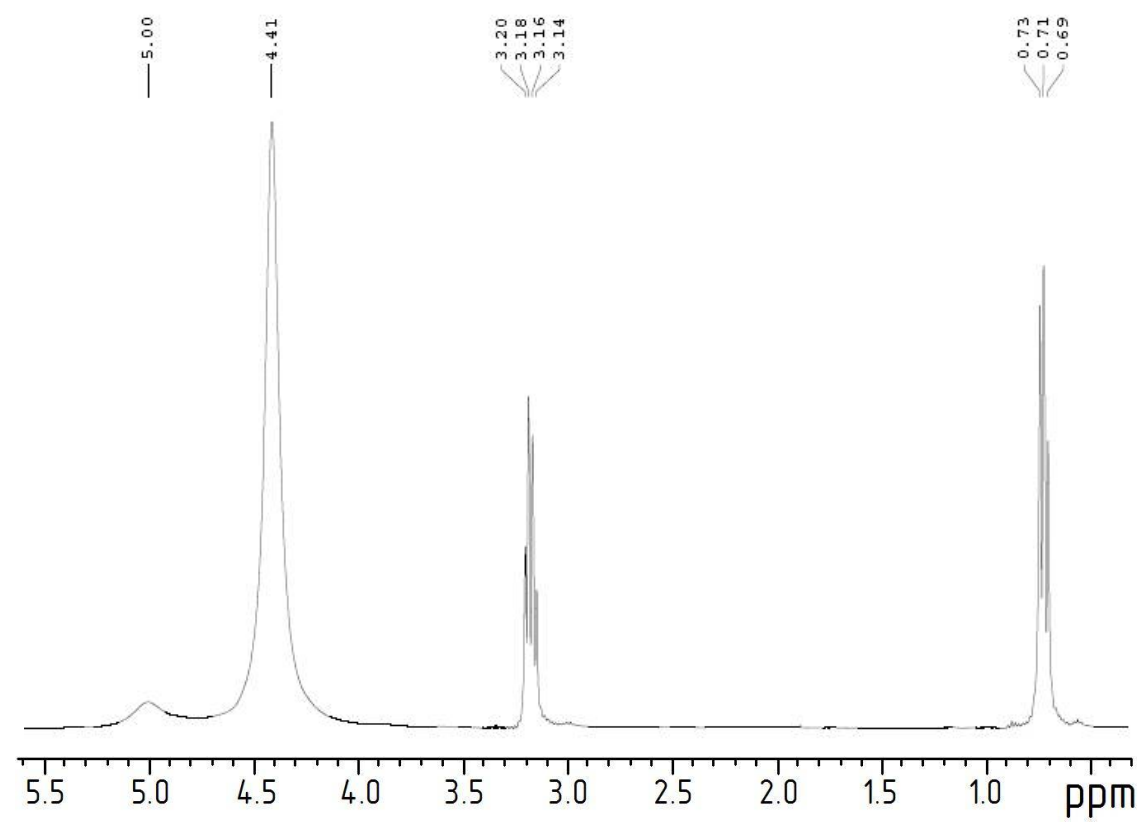

Figure 8. ${ }^{1} \mathrm{HNMR}$ spectra of proton groups of WAM, prepared in demineralized by reverse osmosis water and ERS: $\mathrm{CH}_{3} ; \mathrm{CH}_{2} ; \mathrm{H}_{2} \mathrm{O} ; \mathrm{EtOH}$, dependent from system's functioning time $(60 \mathrm{~h})$ 


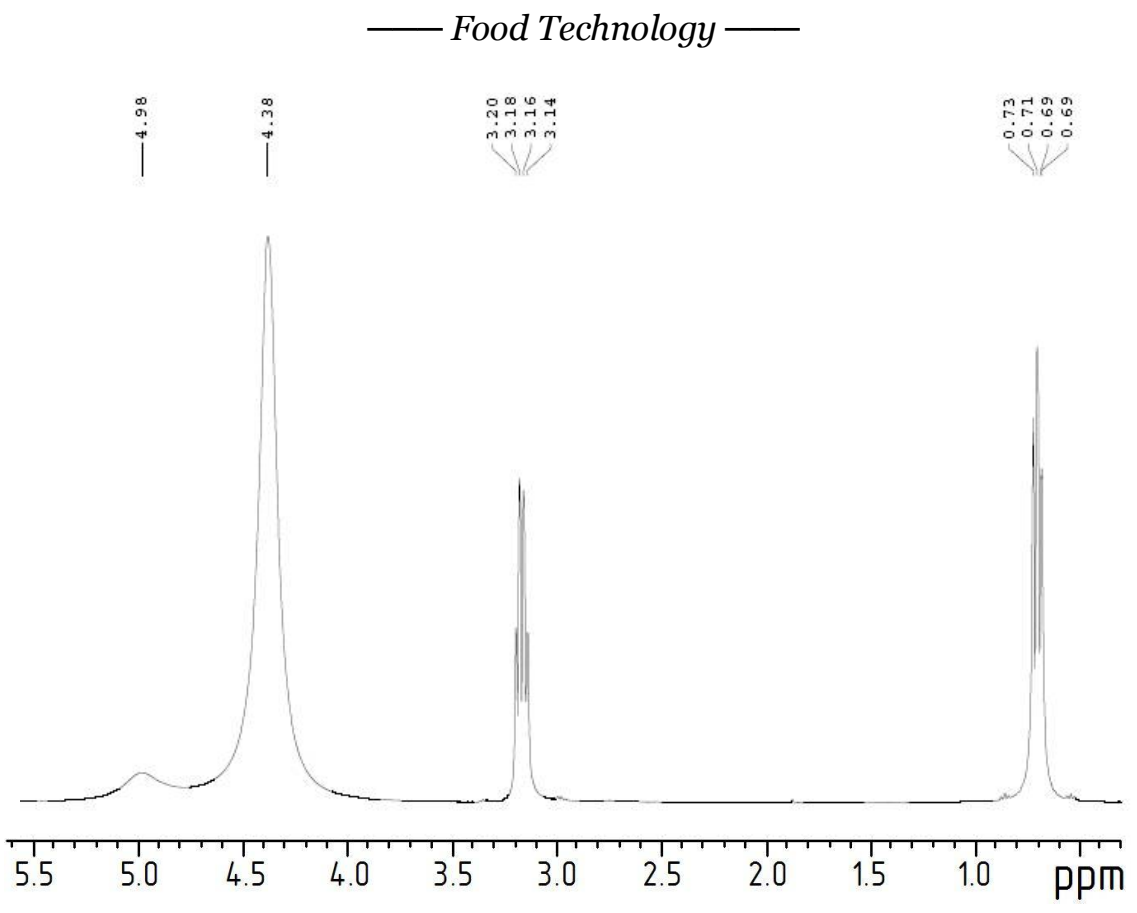

Figure $9 .{ }^{l} \mathrm{H} N M R$ spectra of proton groups of WAM, prepared in demineralized by reverse osmosis water and ERS: $\mathrm{CH}_{3} ; \mathrm{CH}_{2} ; \mathrm{H}_{2} \mathrm{O} ; \mathrm{EtOH}$, dependent from system's functioning time (108 h)

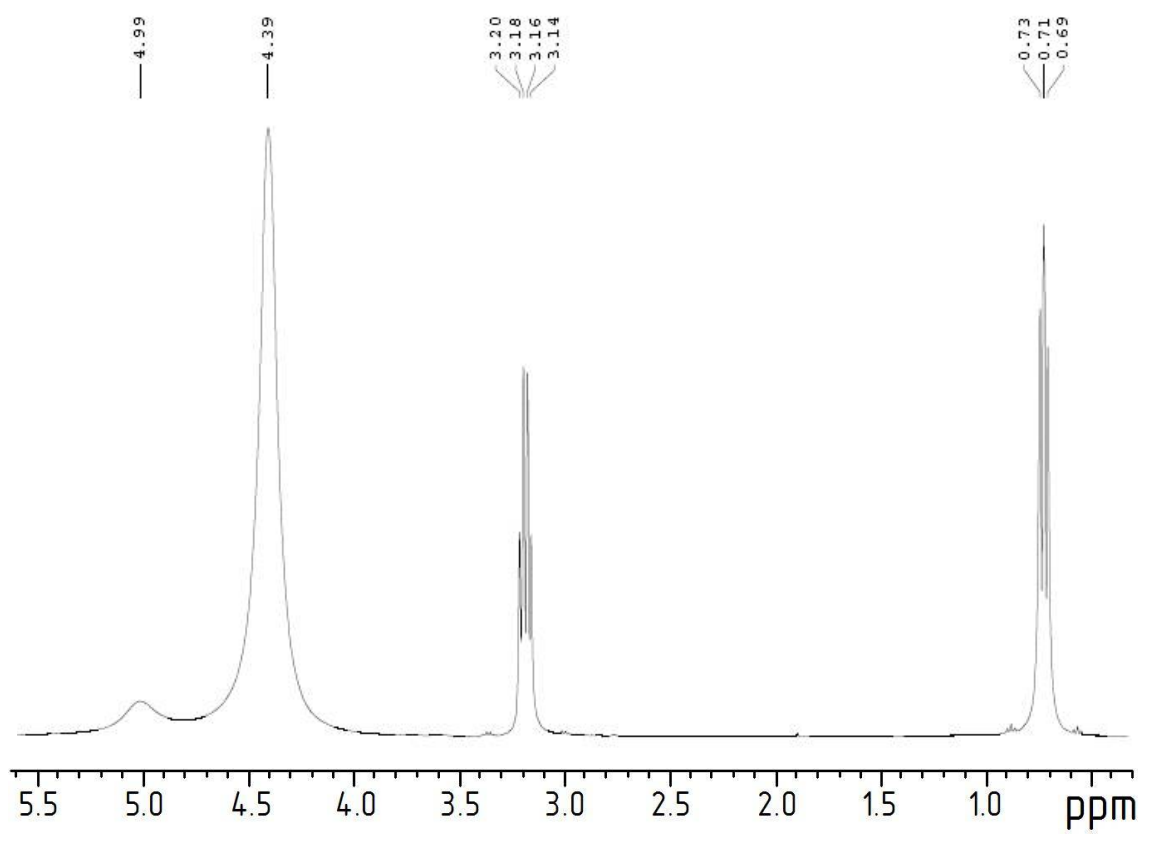

Figure 10. ${ }^{1} \mathrm{H} N M R$ spectra of proton groups of WAM, prepared in demineralized by reverse osmosis water and ERS: $\mathrm{CH}_{3} ; \mathrm{CH}_{2} ; \mathrm{H}_{2} \mathrm{O} ; \mathrm{EtOH}$, dependent from system's functioning time (132 h) 


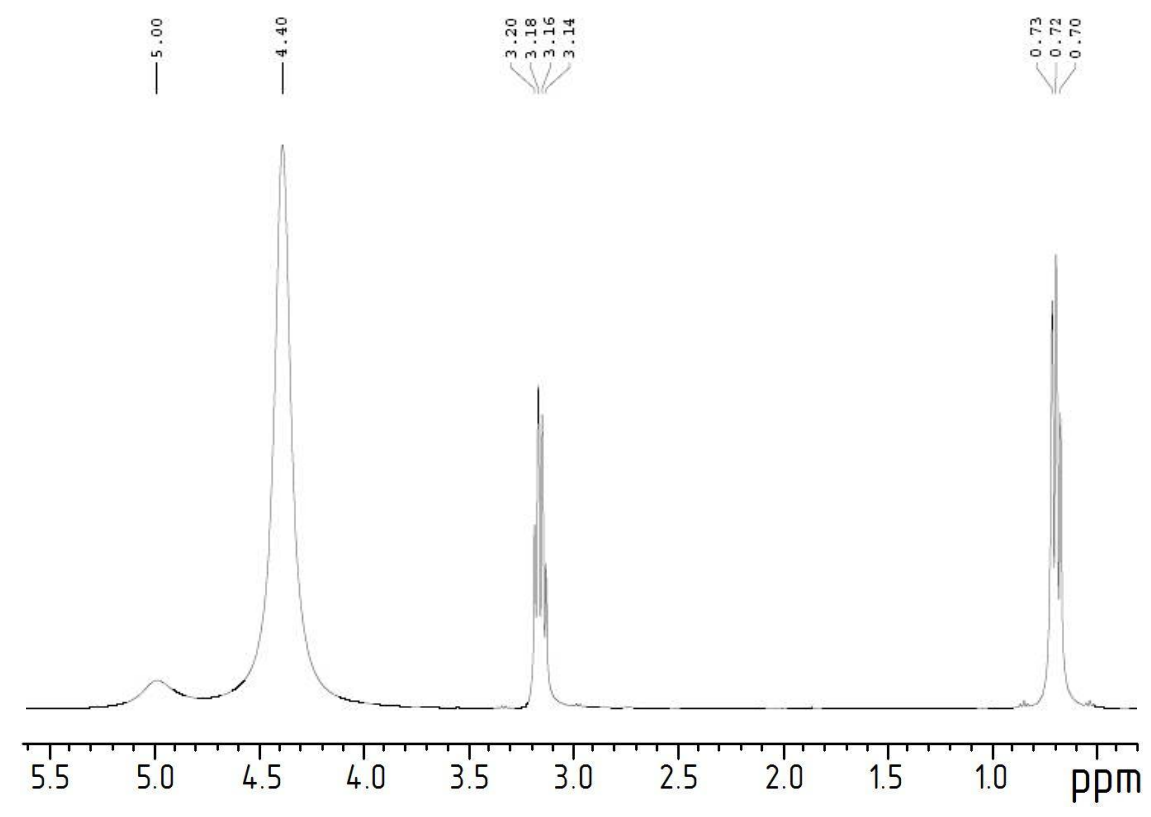

Figure 11. ${ }^{1} \mathrm{H} N M R$ spectra of proton groups of WAM, prepared in demineralized by reverse osmosis water and ERS: $\mathrm{CH}_{3} ; \mathrm{CH}_{2} ; \mathrm{H}_{2} \mathrm{O} ; \mathrm{EtOH}$, dependent from system's functioning time (144 h)

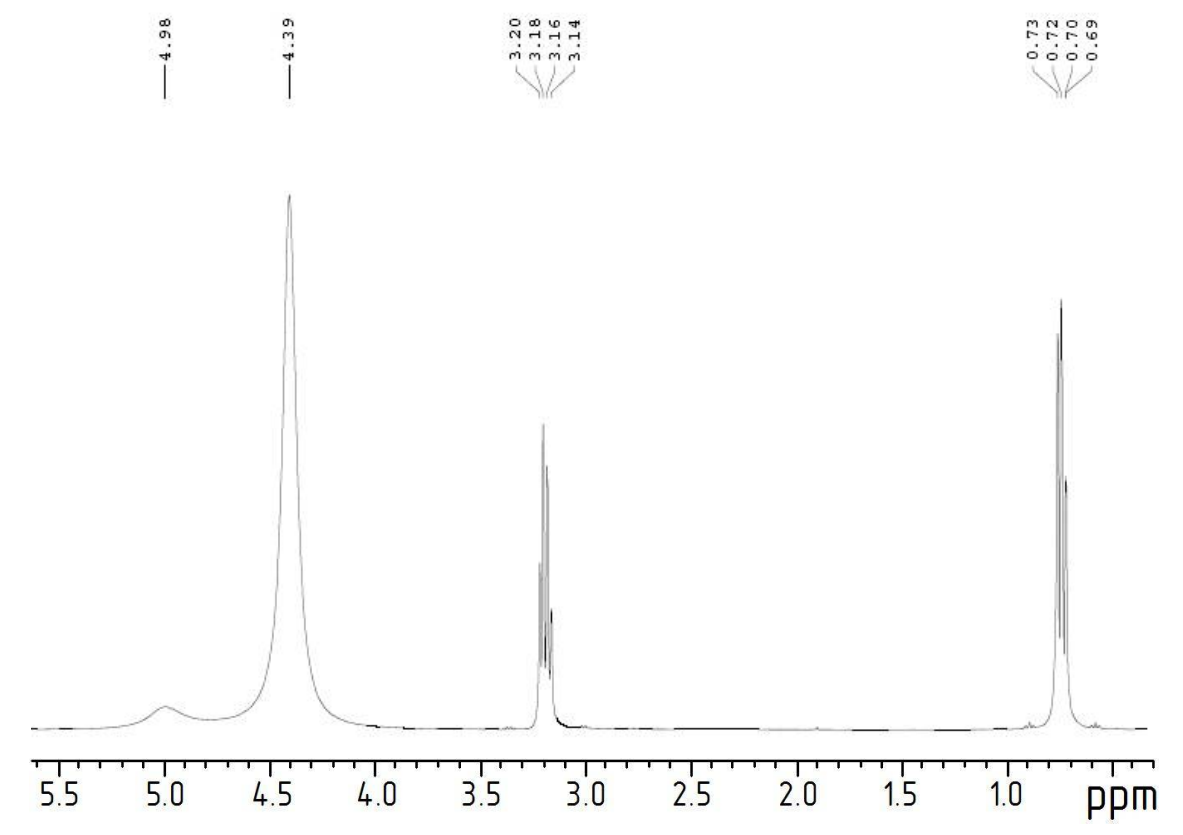

Figure 12. ${ }^{1} \mathrm{H} N M R$ spectra of proton groups of WAM, prepared in demineralized by reverse osmosis water and ERS: $\mathrm{CH}_{3} ; \mathrm{CH}_{2} ; \mathrm{H}_{2} \mathrm{O} ; \mathrm{EtOH}$, dependent from system's functioning time (156 h) 


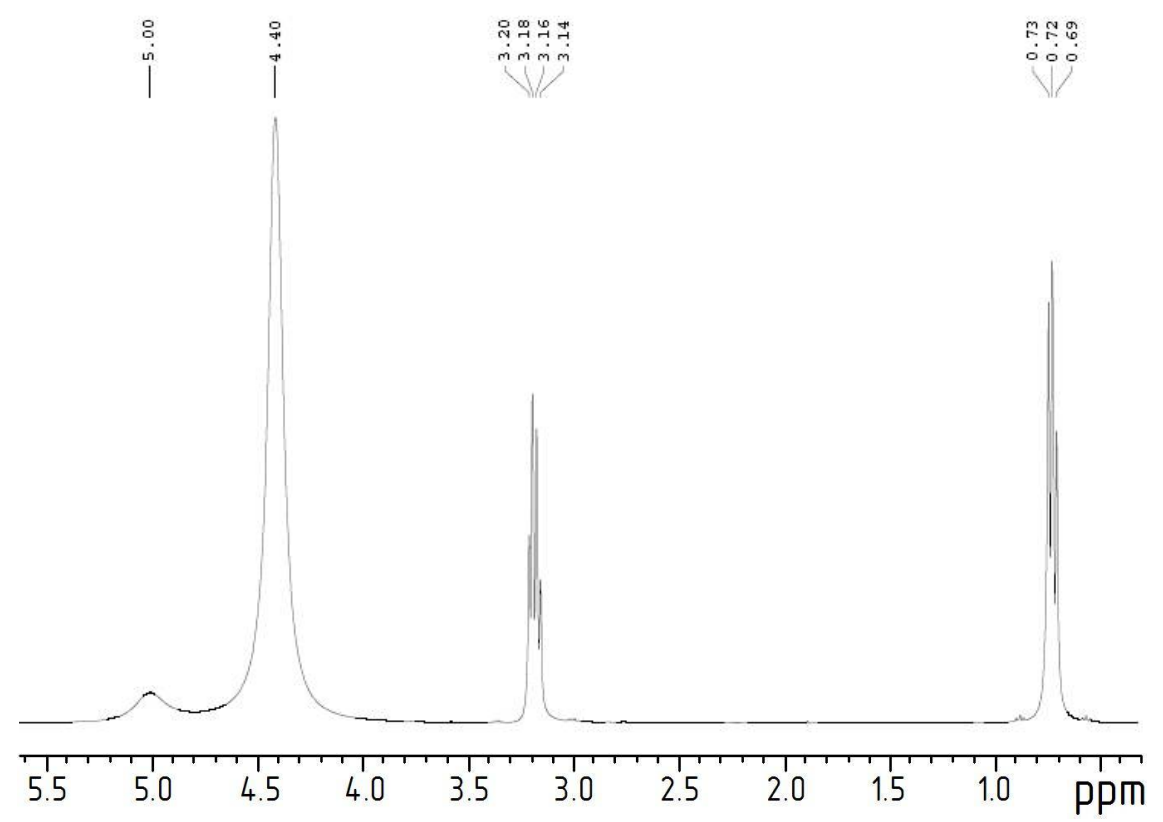

Figure 13. ${ }^{1} \mathrm{H} N M R$ spectra of proton groups of WAM, prepared in demineralized by reverse osmosis water and ERS: $\mathrm{CH}_{3} ; \mathrm{CH}_{2} ; \mathrm{H}_{2} \mathrm{O} ; \mathrm{EtOH}$, dependent from system's functioning time (168 h)

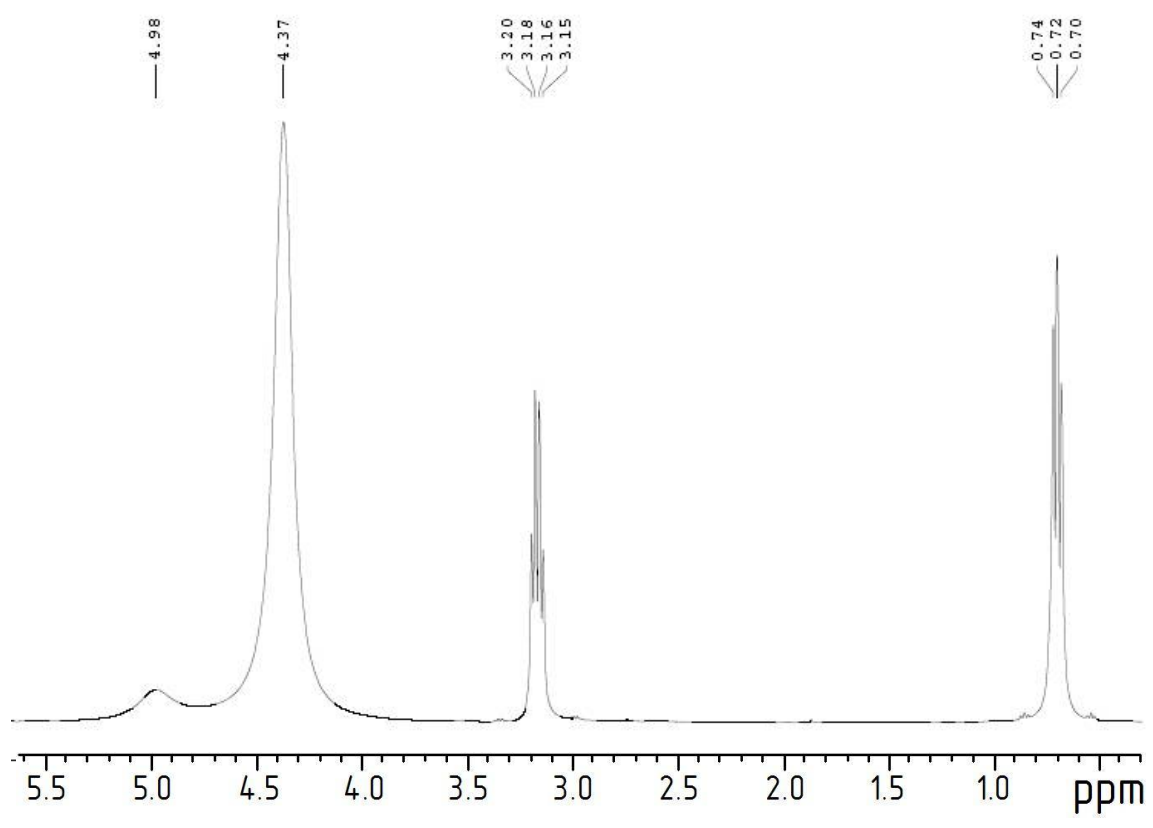

Figure 14. ${ }^{1} \mathrm{H}$ NMR spectra of proton groups of WAM, prepared in demineralized by reverse osmosis water and ERS: $\mathrm{CH}_{3} ; \mathrm{CH}_{2} ; \mathrm{H}_{2} \mathrm{O} ; \mathrm{EtOH}$, dependent from system's functioning time (180 h) 


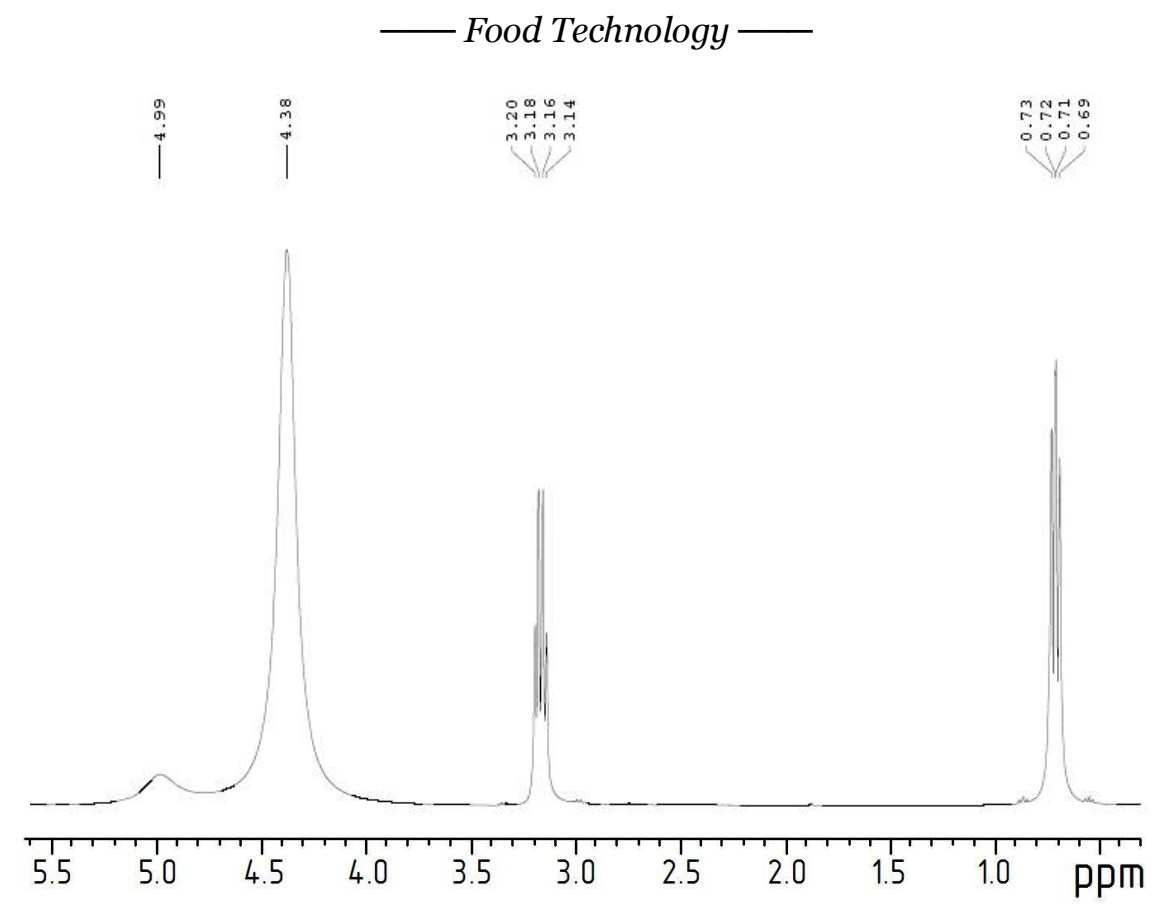

Figure 15. ${ }^{1} \mathrm{H}$ NMR spectra of proton groups of WAM, prepared in demineralized by reverse osmosis water and ERS: $\mathrm{CH}_{3} ; \mathrm{CH}_{2} ; \mathrm{H}_{2} \mathrm{O} ; \mathrm{EtOH}$, dependent from system's functioning time (192 h)

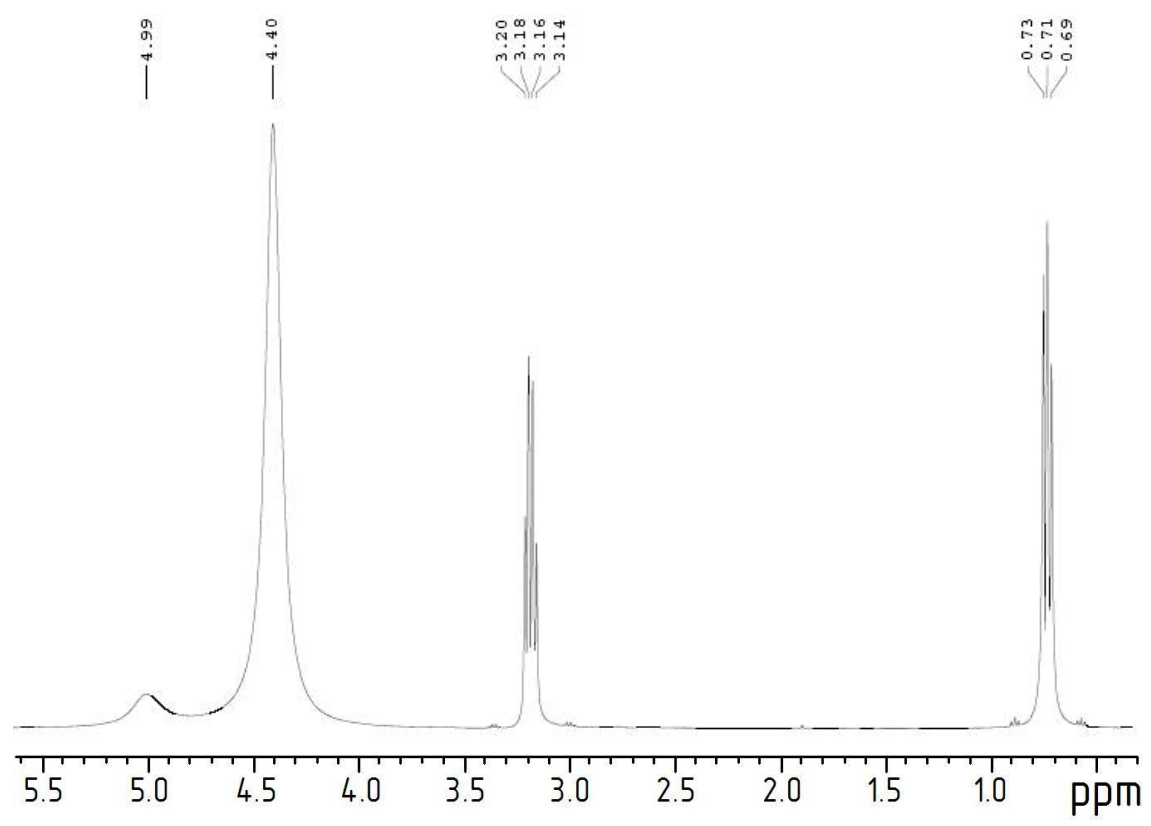

Figure 16. ${ }^{1} \mathrm{H}$ NMR spectra of proton groups of WAM, prepared in demineralized by reverse osmosis water and ERS: $\mathrm{CH}_{3} ; \mathrm{CH}_{2} ; \mathrm{H}_{2} \mathrm{O} ; \mathrm{EtOH}$, dependent from system's functioning time (204 h) 


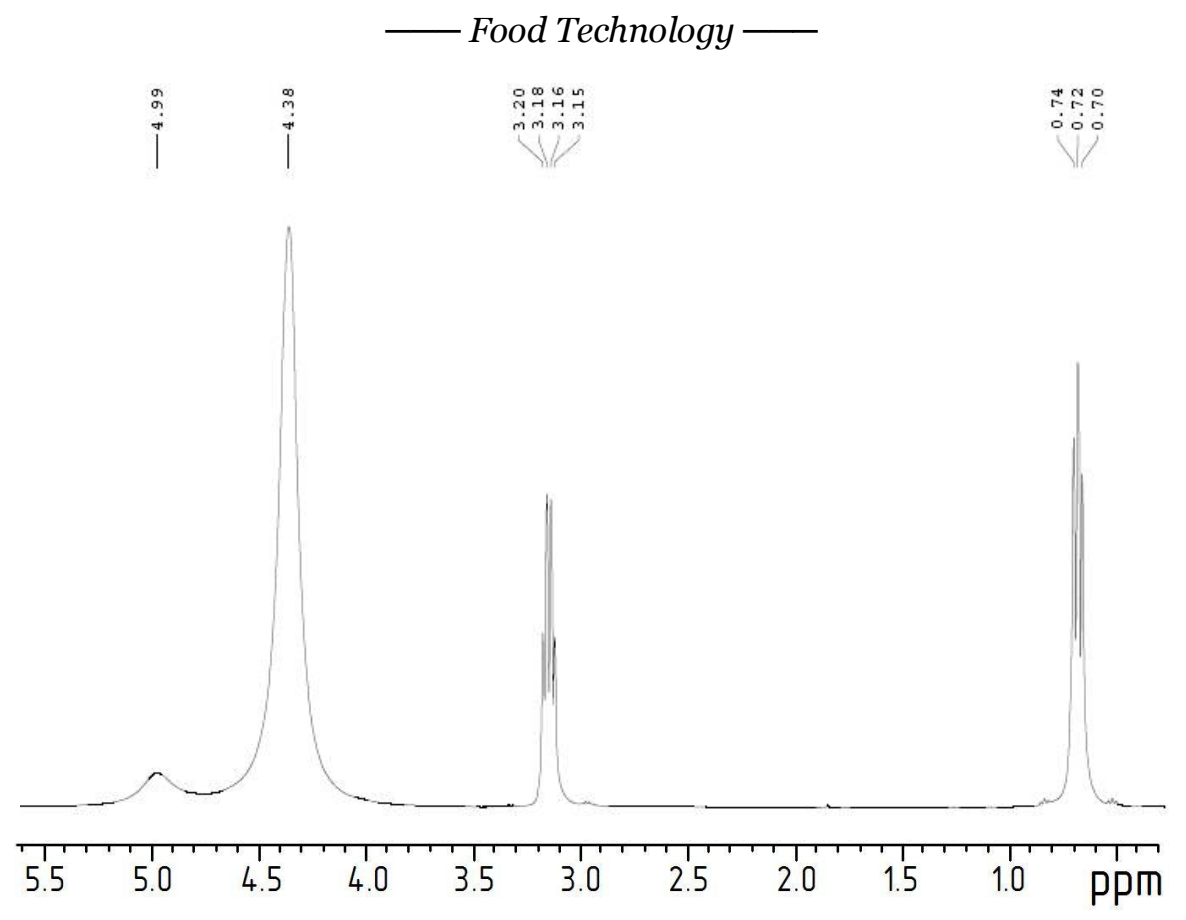

Figure 17. ${ }^{1} \mathrm{H} N M R$ spectra of proton groups of WAM, prepared in demineralized by reverse osmosis water and $\mathrm{ERS}: \mathrm{CH}_{3} ; \mathrm{CH}_{2} ; \mathrm{H}_{2} \mathrm{O} ; \mathrm{EtOH}$, dependent from system's functioning time (216 h)

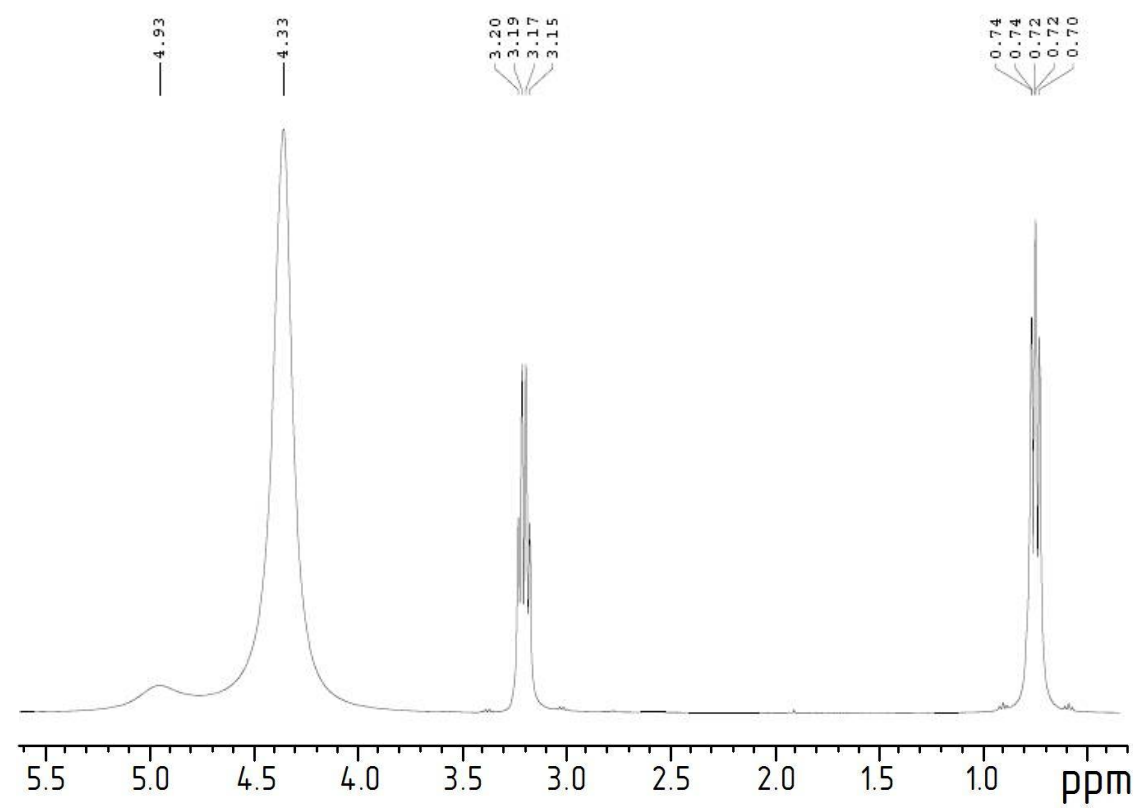

Figure 18. ${ }^{1} \mathrm{H}$ NMR spectra of proton groups of WAM, prepared in demineralized by reverse osmosis water and ERS: $\mathrm{CH}_{3} ; \mathrm{CH}_{2} ; \mathrm{H}_{2} \mathrm{O} ; \mathrm{EtOH}$, dependent from system's functioning time (288 h) 


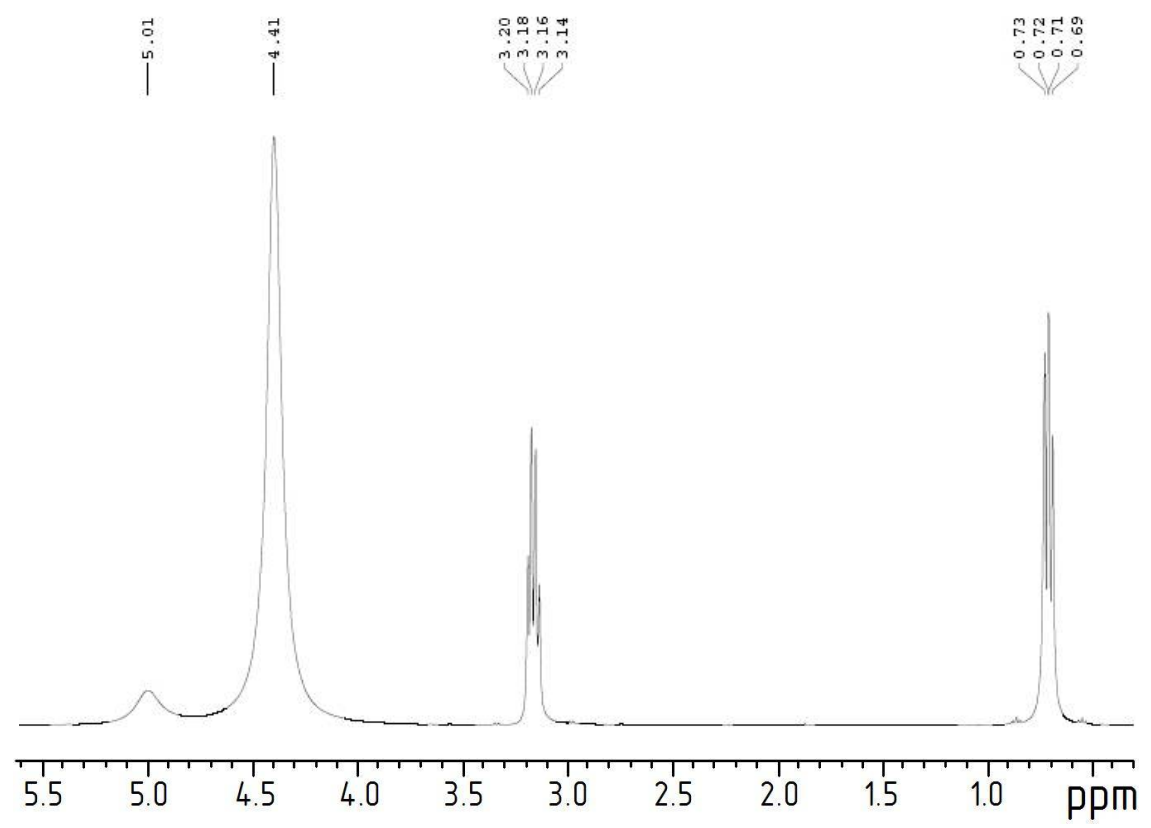

Figure $19 .{ }^{l} H$ NMR spectra of proton groups of WAM, prepared in demineralized by reverse osmosis water and ERS: $\mathrm{CH}_{3} ; \mathrm{CH}_{2} ; \mathrm{H}_{2} \mathrm{O} ; \mathrm{EtOH}$, dependent from system's functioning time (300 h)

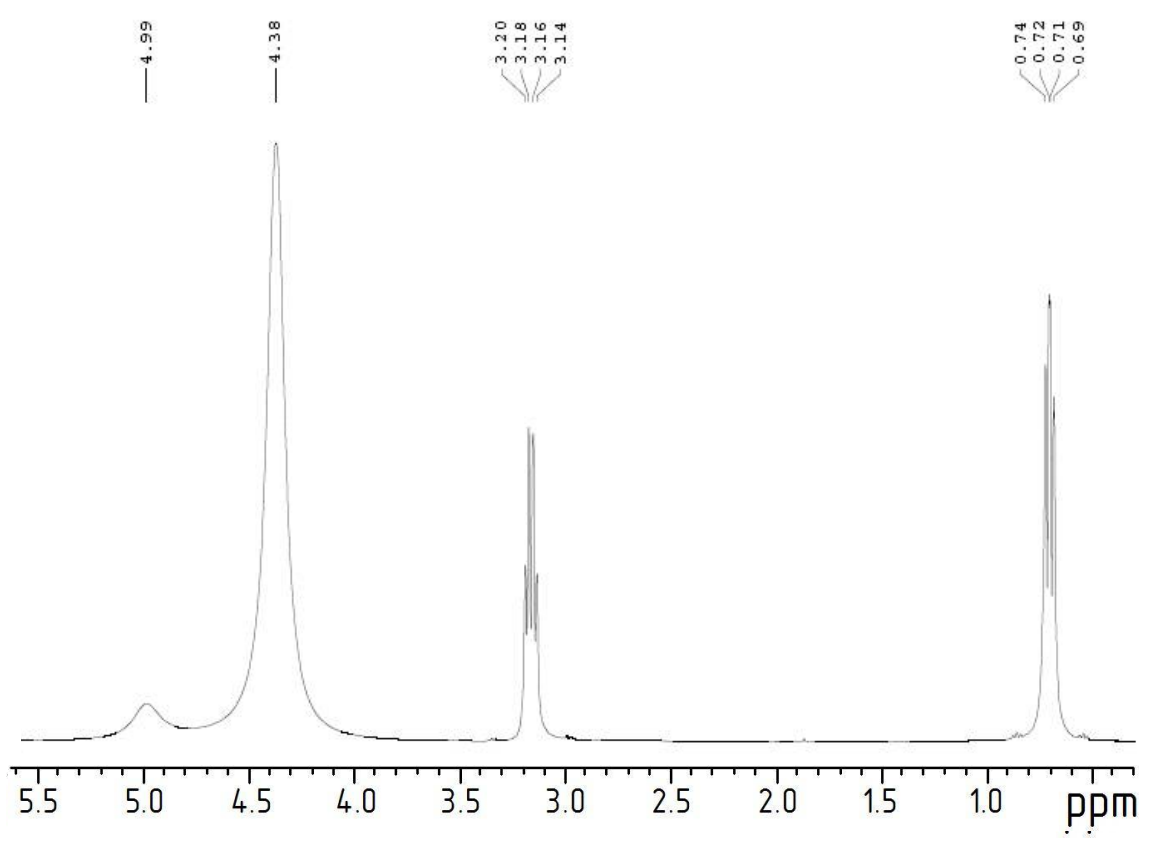

Figure 20. ${ }^{1} \mathrm{H} N M R$ spectra of proton groups of WAM, prepared in demineralized by reverse osmosis water and ERS: $\mathrm{CH}_{3} ; \mathrm{CH}_{2} ; \mathrm{H}_{2} \mathrm{O} ; \mathrm{EtOH}$, dependent from system's functioning time (312 h) 


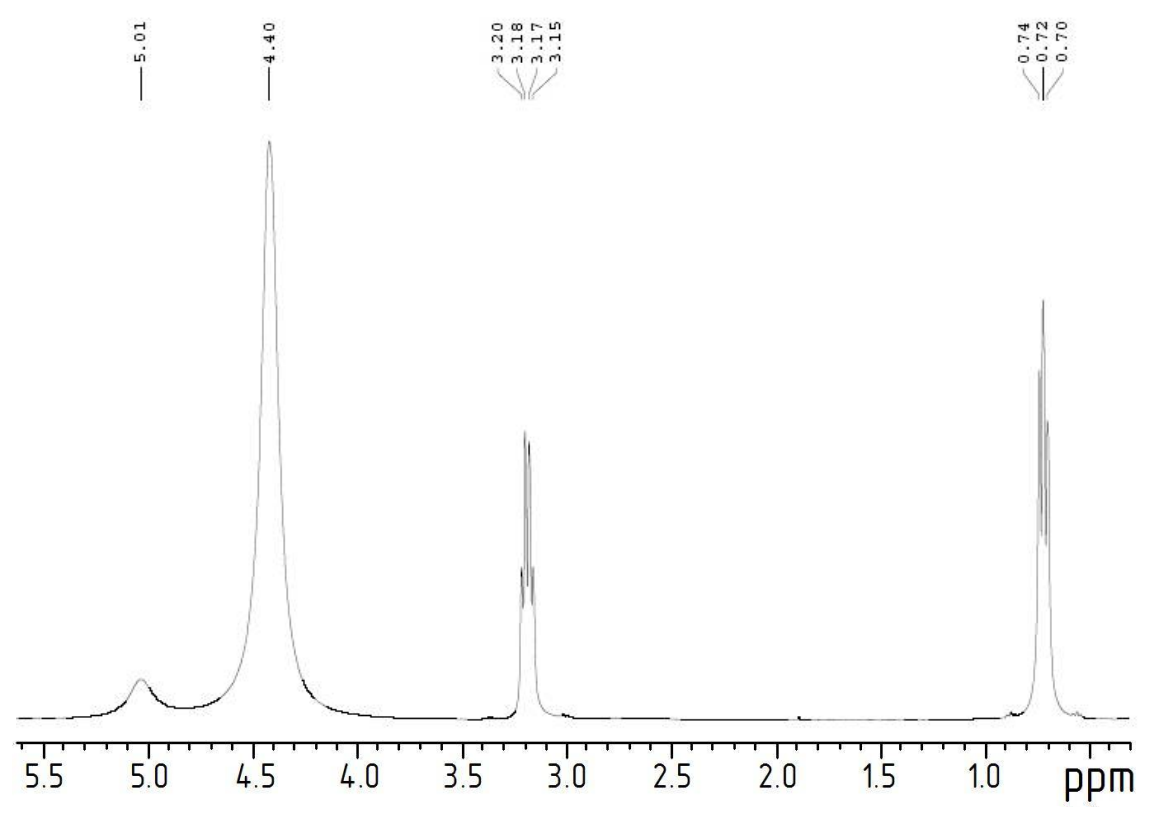

Figure 21. ${ }^{1} \mathrm{H} N M R$ spectra of proton groups of WAM, prepared in demineralized by reverse osmosis water and ERS: $\mathrm{CH}_{3} ; \mathrm{CH}_{2} ; \mathrm{H}_{2} \mathrm{O} ; \mathrm{EtOH}$, dependent from system's functioning time (324 h)

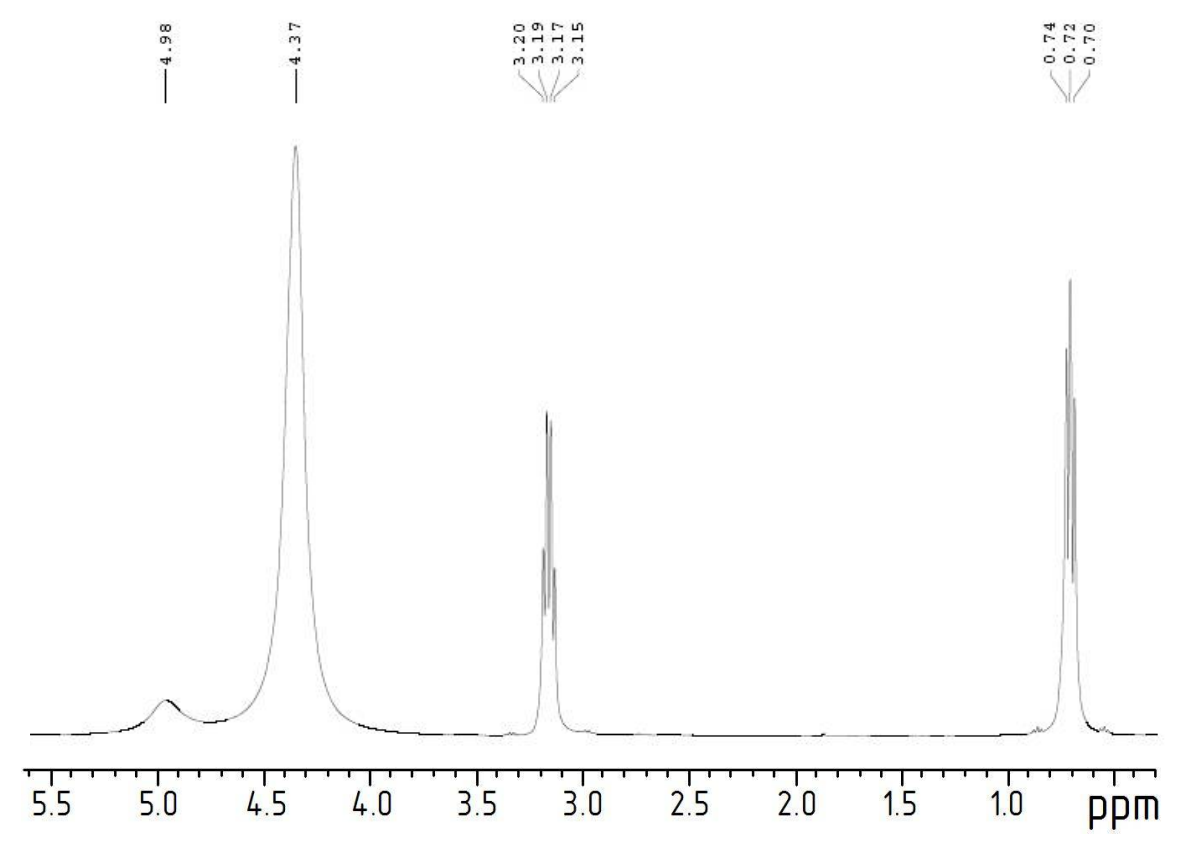

Figure 22. ${ }^{1} \mathrm{H} N M R$ spectra of proton groups of WAM, prepared in demineralized by reverse osmosis water and ERS: $\mathrm{CH}_{3} ; \mathrm{CH}_{2} ; \mathrm{H}_{2} \mathrm{O} ; \mathrm{EtOH}$, dependent from system's functioning time (336 h)

— Ukrainian Food Journal. 2017. Volume 6. Issue 2 — 253 


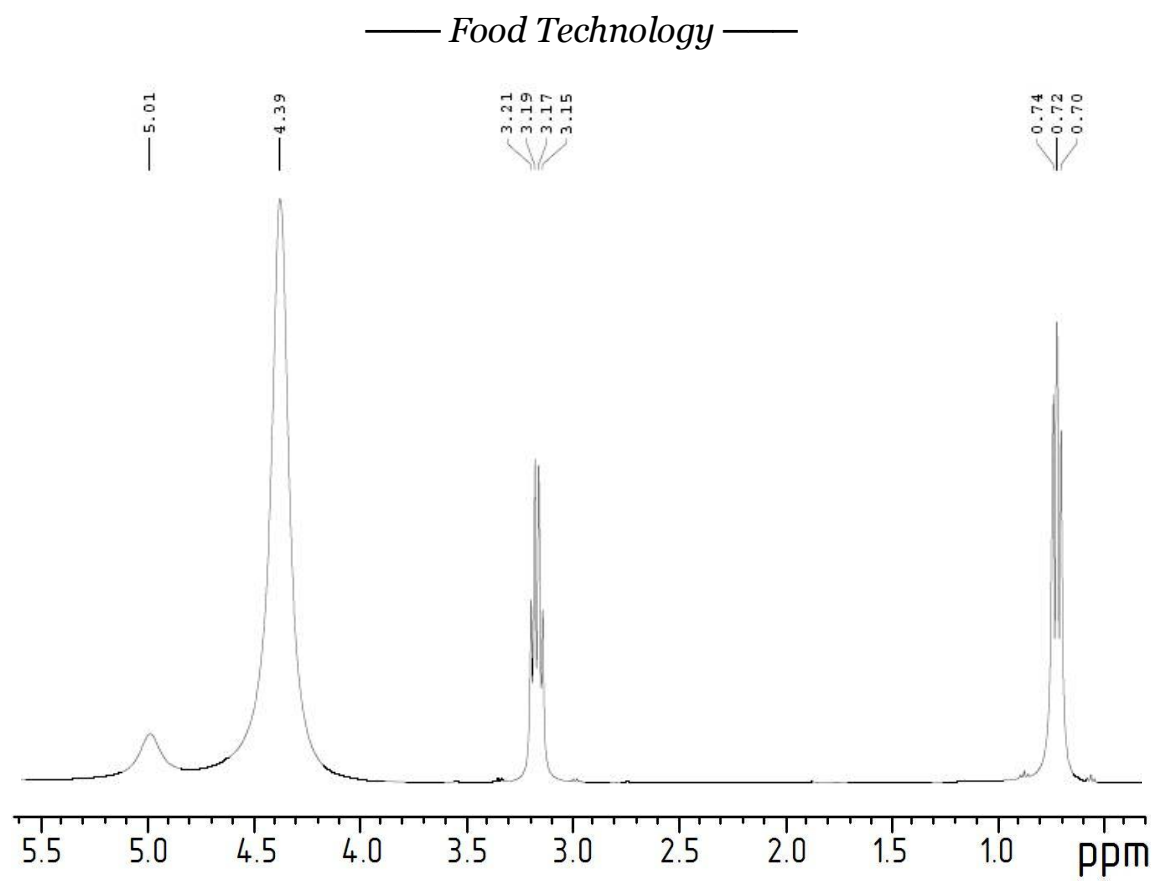

Figure 23. ${ }^{1} \mathrm{H}$ NMR spectra of proton groups of WAM, prepared in demineralized by reverse osmosis water and ERS: $\mathrm{CH}_{3} ; \mathrm{CH}_{2} ; \mathrm{H}_{2} \mathrm{O} ; \mathrm{EtOH}$, dependent from system's functioning time (432 h)

The figures 3-23 shows the proton group's ${ }^{1} H N M R$ spectras of freshly prepared WAM sample $(0 \mathrm{~h})$ and a sample taken after few days, with an interval of $12-72 \mathrm{~h}$ with indication of chemical shift.

At the initial instant of WAM formation $-\tau=0 \mathrm{~h}$ (figure 3 ) the presents of two separate signals $-\mathrm{OH}$ of ethanol $\left(\mathrm{C}_{2} \mathrm{H}_{5} \mathrm{OH}\right)$ and water $\mathrm{H}_{2} \mathrm{O}$ is observed in the area of hydroxyl protons of ethanol and water. Signal of hydroxyl $(\mathrm{OH})$ proton of ethanol $\left(\mathrm{C}_{2} \mathrm{H}_{5} \mathrm{OH}\right)$ is presented in a form of bulge. The bulge is found in a weak field with a chemical shift of $\delta_{E t O H}=4,97 \mathrm{ppm}$. Signal of water $\left(\mathrm{H}_{2} \mathrm{O}\right)$ protons is presented as an elongated singlet of symmetrical shape with a broad base which is located at $\delta_{H 2 O}=4,36 \mathrm{ppm}$. The difference in chemical shifts of $\mathrm{OH}$ proton $\left(\mathrm{C}_{2} \mathrm{H}_{5} \mathrm{OH}\right)$ and $\mathrm{H}_{2} \mathrm{O}$ proton at this stage $(\tau=0 \mathrm{~h})$ is $\Delta \delta_{O H}=0,61$ ppm.

A characteristic feature of hydroxyl proton of ethanol $(\mathrm{EtOH})$ and water $\left(\mathrm{H}_{2} \mathrm{O}\right)$ during the interval of $\tau=12-432 \mathrm{~h}$ (figures $4-23)$ is that the spectra $\left(\delta_{E t O H}=4,93-5,01 \mathrm{ppm}\right.$; $\delta_{H 2 O}=4,33-4,41 \mathrm{ppm}$.) located separately from each other with a difference in a chemical shifts of $\Delta \delta=0,59-0,61 \mathrm{ppm}$. This may indicate that there were no conditions created to form a water composition with hydroxyl proton of alcohol. Therefore, it proves that the state of thermodynamic equilibrium is absent up to $\tau<432 \mathrm{~h}$.

The analysis of ${ }^{l} H$ NMR spectra of WAM methyl group's protons $\left(\mathrm{CH}_{3}\right)$ states the following. $\tau=0$. Methyl group of protons $\left(\mathrm{CH}_{3}\right)$ is represented as a triplet $(t)$ in the initial time of system's operation. Triplet is formed by the spin-spin interaction with protons of adjacent methylene group $\left(\mathrm{CH}_{2}\right)$. The intensity ratio is $(1: 2: 1)$ according to the Pascal triangle. Not a single group of protons can affect methyl group's spectrum $\left(\mathrm{CH}_{3}\right)$ besides the methylene group $\left(\mathrm{CH}_{2}\right)$. Thus, the methyl group of protons $\left(\mathrm{CH}_{3}\right)$ is located in a strong field with an average value of the chemical shift as $\delta_{C H 3}=0,71 \mathrm{ppm}$. 
$\tau=12-432 \mathrm{~h}$. The methyl group of protons $\left(\mathrm{CH}_{3}\right)$ did change its position comparatively to the initial position $(\tau=0 \mathrm{~h})$, and also changed the waveform - from the triplet $(t)$ to the quintet ( $q$ i) and back. The following initial conclusion can be made: the range $(12-432 \mathrm{~h})$ is not characterized by a complete structuring of signal of methyl group $\left(\mathrm{CH}_{3}\right)$ as a triplet $(\mathrm{t})$ as its form and by the middle positioning of a chemical shift $-\delta_{C H 3}=0,70-0,72 \mathrm{ppm}$. There is abnormal change in the spectra's structure during this period of time.

The analysis of ${ }^{l} \mathrm{H} N M R$ spectra of methylene group $\left(\mathrm{CH}_{2}\right)$ reveals the following. At the beginning of the formation of WAM $(\tau=0 \mathrm{~h})$ methylene group of protons $\left(\mathrm{CH}_{2}\right)$ is presented as a quartet $(q)$, which is confirmed by the spin-spin interaction of protons of methyl $\left(\mathrm{CH}_{3}\right)$ groups, that should split signal of the methylene group $\left(\mathrm{CH}_{2}\right)$ into four components, form a quartet $(q)$ with intensity ratio of $1: 3: 3: 1$.

In turn, protons of hydroxyl $(\mathrm{OH})$ group should cleave every component of methylene $\left(\mathrm{CH}_{2}\right)$ group's quartet into two components to form a double quartet. The absence of spin-spin interaction between hydroxyl $(\mathrm{OH})$ and methylene $\left(\mathrm{CH}_{2}\right)$ groups due to chemical exchange would have to ascertain that the signal of the methylene $\left(\mathrm{CH}_{2}\right)$ group must remain as quartet.

Methylene group of protons $\left(\mathrm{CH}_{2}\right)$ has an average value of a chemical shift as $\delta_{\mathrm{CH}_{2}}=3,17$ ppm, distance between each peak of quartet (spin-spin coupling constant) is $8 \mathrm{~Hz}$.

$\tau=12-432 \mathrm{~h}$. Methylene spectrum with an average value of chemical shift $\delta_{\mathrm{CH} 2}=3,17-$ $3,18 \mathrm{ppm}$ is shifted to a weak field by $0,01 \mathrm{ppm}$ relatively to its initial position ( $\tau=0 \mathrm{~h}$ ). Waveform - quartet $(q)$, which is typical for the above proton group, on the assumption of spin-spin interaction with protons of the methyl $\left(\mathrm{CH}_{3}\right)$ group and chemical exchange between the hydroxyl $(\mathrm{OH})$ and methylene $\left(\mathrm{CH}_{2}\right)$ groups.

The following initial conclusion can be made: the range $(0-432 \mathrm{~h})$ is characterized by a complete structuring signal of the methylene group $\left(\mathrm{CH}_{2}\right)$ as quartet $(q)$ in its form and by the middle positioning of the chemical shift $-\delta_{\mathrm{CH}_{2}}=3,17-3,18 \mathrm{ppm}$, which remains unchanged. There is no abnormal change in the spectra's structure during this period of time. Its position can be described as stable. The distance between the peaks also remain unchanged $-0,02$ ppm.

\section{Conclusions}

As a results we have evidence of a complex dynamic of achievement processes of solution equilibrium for WAM prepared in demineralized by reverse osmosis water with $p H=$ 5,05 and ERS. At the same time $p H$ of obtained WAM is $p H=7,60$ i.e. alkalescent medium. A «restoration» of location of hydroxyl proton's signal $(\mathrm{OH})$ of ethanol is not observed during the time interval of 0 to $432 \mathrm{~h}$ after the mixing, with a constant alcohol concentration (WAM's strength $-39,92 \%$ vol.) and system's temperature control $\left(t=23,5^{\circ} \mathrm{C}\right)$. It can be assumed that division of the signals related to the process of reconstruction of water structure that was destroyed by demineralization by reverse osmosis. The low exchange rate (separately observed signals of hydroxyl and water) can be related to a significant microheterogeneity of the system and relevant barrier effect that reduces the effective rate of protons' exchange.

\section{References}

1. Anna Paola Minoja, Claudia Napoli (2014), NMR screening in the quality control of food and nutraceuticals, Food Research International, 63, part B, pp. 126-131.

2. Andoni Zuriarrain, Juan Zuriarrain, Mercedes Villar, Iñaki Berregi (2015), 
Quantitative determination of ethanol in cider by ${ }^{1} \mathrm{H}$ NMR spectrometry, Food Control, 50, pp. 758-762.

3. Arnold J.T., Dharmatti S.S., Packard M.E. (1951), Chemical effects on nuclear induction signals from organic compounds, The journal of chemical physics, 19, pp. 507.

4. Bloch F, Hansen W.W., Packard M. (1946), The nuclear induction experiment, Physical review, 70, pp. 474-489.

5. Nose A., Hamasaki T., Hojo M. and other (2005), Hydrogen bonding in alcoholic beverages (distilled spirits) and water-ethanol mixture, Journal of agricultural and food chemistry, 53, pp. 7074-7081.

6. Richards S.A., Hollerton J.C. (2011), Essential practical NMR for organic chemistry, Chichester: John Wiley \& Sons, Ltd.

7. Roberts J.D. (2002), Organic chemistry applications, in Grant, D.M., Harris, R.K. (ed.) Encyclopedia of nuclear magnetic resonance, Chichester: John Wiley \& Sons, Ltd, pp. $3386-3400$.

8. Hu N., Wu D., Cross K. and other (2010), Structurability: A collective measure of the structural differences in vodkas, Journal of agricultural and food chemistry, 58, pp. 7394-7401.

9. Matsugami M., Yamamoto R., Kumai T., Tanaka M., Takamuku T. (2016), Hydrogen bonding in ethanol-water and trifluoroethanol-water mixtures studied by NMR and molecular dynamics simulation, Journal of Molecular Liquids, 217, pp. 3-11.

10. Manazael Z. Jora, Marcus V.C. Cardoso, Edvaldo Sabadini (2017), Correlation between viscosity, diffusion coefficient and spin-spin relaxation rate in ${ }^{1} \mathrm{H}$ NMR of water-alcohols solutions, Journal of Molecular Liquids, 238, pp. 341-346.

11. Latufa Youssouf, Laura Lallemand, Pierre Giraud, Faiza Soulé, Joël Couprie (2017), Ultrasound-assisted extraction and structural characterization by NMR of alginates and carrageenans from seaweeds, Carbohydrate Polymers, 166, pp. 55-63.

12. Gloria del Campo, Juan Zuriarrain, Andoni Zuriarrain, Iñaki Berregi (2016), Quantitative determination of carboxylic acids, amino acids, carbohydrates, ethanol and hydroxymethylfurfural in honey by ${ }^{1} \mathrm{H}$ NMR, Food Chemistry, 196, pp. 10311039.

13. Kawarpal Singh, Bernhard Blümich (2016), NMR spectroscopy with compact instruments, TrAC Trends in Analytical Chemistry, 83, Part A, pp. 12-26.

14. Fan Zhu (2017), NMR spectroscopy of starch systems, Food Hydrocolloids, 63, pp. 611-624.

15. Yunfei Yuan, Yupeng Zhao, Jiali Yang, Yueming Jiang, Bao Yang (2017), Metabolomic analyses of banana during postharvest senescence by ${ }^{1} \mathrm{H}$-high resolutionNMR, Food Chemistry, 218, pp. 406-412.

16. Hore P.J. (2017), NMR Principles, Encyclopedia of Spectroscopy and Spectrometry (Third Edition), pp. 187-194.

17. Cherif Ibrahima Khalil Diop, Hai Long Li, Peng Chen, Bi Jun Xie (2012), Properties of maize starch modified by ball milling in ethanol medium and low field NMR determination of the water molecular mobility in their gels, Journal of Cereal Science, 56 (2), pp. 321-331.

18. Ye Tian, Jaana Liimatainen, Aino-Liisa Alanne, Anni Lindstedt, Baoru Yang (2017), Phenolic compounds extracted by acidic aqueous ethanol from berries and leaves of different berry plants, Food Chemistry, 220, pp. 266-281.

19. N.R. Sucupira, E.G. Alves Filho, L.M.A. Silva, E.S. de Brito, P.H.M. Sousa (2017), NMR spectroscopy and chemometrics to evaluate different processing of coconut 
water, Food Chemistry, 216, pp. 217-224.

20. Bao Qiong Li, Min Li Xu, Xue Wang, Hong Lin Zhai, Jin Jin Liu (2017), An approach to the simultaneous quantitative analysis of metabolites in table wines by ${ }^{1} \mathrm{H}$ NMR self-constructed three-dimensional spectra, Food Chemistry, 216, pp. 52-59.

21. Elena Shumilina, Rasa Slizyte, Revilija Mozuraityte, Anastasiya Dykyy, Alexander Dikiy (2016), Quality changes of salmon by-products during storage: Assessment and quantification by NMR, Food Chemistry, 211, pp. 803-811.

22. Alex O. Okaru, Kennedy O. Abuga, Isaac O. Kibwage, Thomas Hausler, Dirk W. Lachenmeier (2017), Aflatoxin contamination in unrecorded beers from Kenya - A health risk beyond ethanol, Food Control, 79, pp. 344-348.

23. Kuzmin O., Sujkov S., Topol'nik V. (2013), The change of the hydroxyl protons in aqueous alcoholic mixtures under the process of making vodkas, The advanced science journal, Special issue in China, pp. 15-27.

24. Kuzmin O., Topol'nik V. (2014), Eduction of unsteady equilibrium in vodkas by means of ${ }^{1} \mathrm{H}$ NMR spectroscopy, The advanced science journal, 10, pp. 43-46.

25. Kuzmin O., Topolnyk V., Myronchuk V. (2014), Eduction of equilibrium state in vodkas by means of ${ }^{1} \mathrm{H}$ NMR spectroscopy, Ukrainian Journal of Food Science, 2 (2), pp. $220-228$.

26. Kuzmin O. (2015), Determination of systems with a steady equilibrium in vodkas, depending on transformation of hydroxyl protons, Ukrainian Journal of Food Science, 3 (1), pp. 33-41. 